\title{
A Proximal Bisnitroxide Initiator: Studies in Low-Temperature Nitroxide-Mediated Polymerizations
}

\author{
Jean Ruehl' ${ }^{\dagger}$, Nicole L. Hill ${ }^{\dagger}$, Eric D. Walter, Glenn Millhauser, and Rebecca Braslau ${ }^{*}$ \\ Department of Chemistry and Biochemistry, University of California, Santa Cruz, California 95064
}

\section{Abstract}

Nitroxide-mediated "living" radical polymerization with bisalkoxyamine 2,5,5,8,8,11-

hexamethyl-4,9-(1-phenylethoxy)-3,10-diphenyl-4,9-diazadodecane produces polymers of controlled length and narrow molecular weight distributions at temperatures ranging from 70 to $110^{\circ} \mathrm{C}$. Polymerizations were run successfully with styrene (St), tert-butyl acrylate $(t \mathrm{BA})$, and dimethylacrylamide (DMA). EPR measurements of the homolysis of this bisalkoxyamine and monoalkoxyamine 2,2,5-trimethyl-3-(1-phenylethoxy)-4-phenyl-3-azahexane at temperatures ranging from 85 to $105^{\circ} \mathrm{C}$ give rate constants for the bisalkoxyamine that are approximately twice as large as those for the monoalkoxyamine. ${ }^{1} \mathrm{H}$ NMR investigations of the decomposition of both alkoxyamines at $125^{\circ} \mathrm{C}$ show enhanced decomposition for the bisalkoxyamine. EPR decomposition studies at $120^{\circ} \mathrm{C}$ on the corresponding bis- and mononitroxides $2,5,5,8,8,11$ hexamethyl-3,10-diphenyl-4,9-diazadodecane-4,9-bisnitroxide and 2,2,5-trimethyl-4-phenyl-3azahexane-3-nitroxide also show accelerated bisnitroxide decomposition. Low-temperature EPR studies of the bisnitroxide reveal an unusually strong radical-radical interaction, suggesting enhanced stabilization of the intermediate mononitroxide formed during polymerization by interaction with the proximal $\mathrm{N}$-alkoxyamine. The transient mononitroxide is postulated to be stabilized by delocalization of the unpaired electron density over five atoms.

\section{Introduction}

Controlled free radical polymerization techniques, such as nitroxide-mediated radical polymerization ${ }^{1-5}$ (NMRP), atom transfer radical polymerization, ${ }^{6-17}$ and reversible addition fragmentation transfer, ${ }^{18-24}$ provide the opportunity to prepare a variety of welldefined macromolecules with designed architectures. ${ }^{25}$ The radical nature of the intermediates makes these methods very chemoselective, allowing polymerization in the presence of many functionalities without the need for protecting groups. These "living" techniques provide control over the molecular weight of the resulting polymers and maintain low polydispersities. ${ }^{26-28}$ The use of unimolecular initiators allows for the preparation of a variety of morphologies including linear polymers, graft polymers, and star polymers. ${ }^{29}$ NMRP forms polymers devoid of metal contaminates. The use of $\alpha$-hydrogen bearing nitroxides $4,5,30-32$ allows the formation of block copolymers with a variety of olefin monomers using a single nitroxide as the mediating agent. Despite the great promise of NMRP, most NMRP applications to date require relatively high temperatures: typically between 120 and $135^{\circ} \mathrm{C} .{ }^{1}$

\footnotetext{
"Corresponding author: voice mail (831) 459-3087; Fax (831) 459-2935; braslau @ chemistry.ucsc.edu.

†These authors contributed equally.

Supporting Information Available: Data tables for polymerizations at 90 and $110{ }^{\circ} \mathrm{C}$, kinetic plots and GPC traces for monomer polymerization time studies, data table for ABA triblock copolymers, concentration vs time plots and Arrhenius plot for the thermal homolysis EPR experiments, concentration vs time plots from the ${ }^{1} \mathrm{H}$ NMR and EPR decomposition experiments, and derivation of eq

1. This material is available free of charge via the Internet at http://pubs.acs.org.
} 
In the past several years significant effort has gone into the development of nitroxide-based initiators that effect controlled polymerization at temperatures lower than the typical conditions of $120^{\circ} \mathrm{C}$. Jérôme et al. ${ }^{33,34}$ screened a series of nitrones for in situ nitroxide formation for the polymerization of styrene, styrene/acrylonitrile mixtures, and dienes at 110 ${ }^{\circ} \mathrm{C}$. Additionally, they were successful with the polymerization of tert-butyl methacrylate in water at $80{ }^{\circ} \mathrm{C} .{ }^{35}$ Catala et al. ${ }^{36,37}$ extensively studied the polymerization of styrene, ethyl acrylate, and $n$-butyl acrylate at temperatures as low as $90{ }^{\circ} \mathrm{C}$ using a stable $\beta$-sulfinyl nitroxide. Hawker et al. ${ }^{38}$ demonstrated that a nitroxide capable of intramolecular $\mathrm{H}$ bonding ${ }^{39}$ is an efficient way to accelerate the polymerization of styrene and acrylate monomers. Studer et al. ${ }^{31,40-43}$ synthesized several structurally diverse $\mathrm{N}$-alkoxyamines for use in NMRP with an emphasis on increasing the nitroxide steric bulk and examining the effect of cyclic nitroxide ring size. In some cases, control was achieved at temperatures as low at $70{ }^{\circ} \mathrm{C}$. Charleux has effected polymerization of methyl methacrylate and methacrylic acid by NMRP at $60-90{ }^{\circ} \mathrm{C}$ with the addition of small amounts of styrene. ${ }^{44,45}$ Greci and Bertin have recently developed a new class of nitroxides for the polymerization of methyl methacrylate at $100^{\circ} \mathrm{C} .46$

Recently we reported bisnitroxide-based initiator 2,5,5,8,8,-11-hexamethyl-4,9-(1phenylethoxy)-3,10-diphenyl-4,9-diaza-dodecane 1 (Figure 1) for use in NMRP. ${ }^{47}$ This bidirectional initiator effects polymerization in a well-controlled manner at $120^{\circ} \mathrm{C}$; there is a linear correlation between molecular weight and conversion and good control of polydispersity with a variety of monomers. The addition of a second B block is facile, resulting in symmetrical ABA triblock copolymers, with the B block inserted into the center of the macroinitiator. The design of this bisalkoxyamine was based on the parent monodirectional 2,2,5-trimethyl-4-phenyl-3-azahexane-3-nitroxide (TIPNO) initiator 2. ${ }^{4}$ Interestingly, although the structures of these two initiators are similar, it was observed that polymerizations run with bisalkoxyamine 1 reached significantly higher percent conversions than those run with initiator $\mathbf{2}$ under identical conditions. Investigations using a macromolecular monodirectional nitroxide initiator demonstrated that nitroxide size is not responsible for this enhanced rate. ${ }^{48}$ Herein is demonstrated the ability of $\mathbf{1}$ to carry out lowtemperature polymerizations with a selection of monomers. To probe the reason that this initiator is effective at low temperatures, electron paramagnetic resonance (EPR) studies were performed to determine the dissociation rate constants $\left(k_{\mathrm{d}}\right)$ and the activation energies $\left(E_{\mathrm{a}}\right)$ for the homolysis of $\mathbf{1}$ as compared to $\mathbf{2}$. In addition, the rates of decomposition of the alkoxyamines were examined by ${ }^{1} \mathrm{H}$ NMR, and the rates of decomposition of the corresponding bis- and mononitroxides 2,5,5,8,8,11-hexamethyl-3,10-diphenyl-4,9diazadodecane-4,9-bisnitroxide (3) and 2,2,5-trimethyl-4-phenyl-3-azahexane-3-nitroxide (4) were examined by high-temperature EPR. Interestingly, evaluation of the lowtemperature EPR spectra of $\mathbf{3}$ at $130 \mathrm{~K}$ revealed a surprisingly large spin-spin interaction between the two nitroxide moieties. These results suggest a new mode of stabilization for the key intermediate mononitroxide.

\section{Experimental Section}

\section{General Materials and Methods}

Styrene (St) (99\%, Acros Organics), tert-butyl acrylate ( $t \mathrm{BA})$ (98\%, Aldrich), $n$-butyl acrylate $(n \mathrm{BA})(99+\%$, Acros Organics), and dimethylacrylamide (DMA) $(99 \%$, Aldrich) were distilled under vacuum immediately before use. 2,2,6,6-Tetramethylpiperidinoxy (TEMPO) (98\%, Acros Organics), tert-butylbenzene (99\%, Alfa Aesar), and $p$-xylene- $d_{10}$ (Sigma Aldrich) were used as received. Polymerizations were carried out in sealed ampules. The synthesis and full characterization of $\mathbf{1}$ and $\mathbf{3}$ have been previously reported; ${ }^{47} \mathbf{2 , 4}$, and 2,2,6,6-tetramethyl-1-(1-phenylethoxy)piperidine (5) are also reported. ${ }^{4,49}$ For EPR 
experiments, nitroxide $\mathbf{3}$ was purified by flash chromatography (90:10 hexanes/ethyl acetate), and compounds 1-4 were all synthesized within $48 \mathrm{~h}$ of use.

\section{Analytical Techniques}

NMR spectra were recorded at $500 \mathrm{MHz}$ (Varian) as noted in $\mathrm{CDCl}_{3}$. Gel permeation chromatography (GPC) was performed using a Waters apparatus equipped with five Styragel columns $(300 \times 4.6 \mathrm{~mm}, 5 \mu \mathrm{m}$ bead size), HR 0.5 (pore size: $50 \AA$, $0-1000 \mathrm{Da}), \mathrm{HR}$ 1 (pore size: $100 \AA$, 100-5000 Da), HR 2 (pore size: 500 ̊, 500-20 000 Da), HR 4 (pore size: $10000 \AA$, 50-100 $000 \mathrm{Da}$ ), HR 5E (linear bed, mixed pore sizes, 2000-4 × 10 6 Da). Tetrahydrofuran (THF) was used as the eluent at a flow rate of $0.35 \mathrm{~mL} / \mathrm{min}$ at ambient temperature. A refractive index detector was used and the molecular weights were calibrated against seven polystyrene standards ranging from 2000 to $156000 \mathrm{Da}$.

\section{EPR Experiments}

EPR measurements were taken on a Bruker EMX spectrometer fitted with a variable temperature probe and SHQ cavity. All samples were run in capped EPR tubes in tertbutylbenzene. Freshly synthesized samples were prepared for all experiments. The microwave frequency was $9.44 \mathrm{GHz}$ and power was $0.2 \mathrm{~mW}$. The field was swept $75 \mathrm{G}$ in $10.5 \mathrm{~s}$ with a time constant of $41 \mathrm{~ms}$. The field was modulated at $100 \mathrm{kHz}$ at an amplitude of $0.5 \mathrm{G}$.

For C-O bond homolysis experiments, EPR spectra of bisalkoxyamine $1(0.601 \mathrm{mM}$ of initiator; $1.20 \mathrm{mM}$ of alkoxyamine functionality) and TIPNO-based initiator $2(1.20 \mathrm{mM})$ were recorded every $15 \mathrm{~s}$. Air was used as a radical scavenger. ${ }^{50}$ The evolution of nitroxide was monitored by calculating the second integral of the EPR signal at each time point. These values were converted to concentrations with the use of standardized calibration curves from freshly prepared solutions of TEMPO $(0.603$ and $0.308 \mathrm{mM})$. The experiments were repeated (including the standardized curves) with the temperature fixed at 358, 363, 368, 373 , and $378 \mathrm{~K}$. The initial slope ${ }^{51}$ of a plot of nitroxide concentration vs time was used to determine $k_{\mathrm{d}}$. The derivation of this initial slope method for a bisalkoxyamine is given in the Supporting Information.

For nitroxide decomposition experiments, EPR spectra of bisnitroxide $3(2.02 \mathrm{mM}$ of initiator; $4.04 \mathrm{mM}$ of nitroxide functionality) were recorded every $30 \mathrm{~s}$, and EPR spectra of mononitroxide $4(4.03 \mathrm{mM})$ were recorded every $60 \mathrm{~s}$. These experiments were run at 120 ${ }^{\circ} \mathrm{C}$.

EPR spectra that were used to determine the interspin distance in 1 were recorded at $130 \mathrm{~K}$ (frozen solution). Microwave power was $0.2 \mathrm{~mW}$ for full field and $100 \mathrm{~mW}$ for half-field spectra. The field was swept $300 \mathrm{G}$ in $83 \mathrm{~s}$ with a time constant of $327 \mathrm{~ms}$. The field was modulated at $100 \mathrm{kHz}$ at an amplitude of $1 \mathrm{G}$.

\section{NMR Studies}

Following the procedure of Cameron et al., ${ }^{32}$ a solution of bisalkoxyamine initiator $\mathbf{1}$ in $p$ xylene- $d_{10}(90 \mathrm{mM}$ of initiator; $180 \mathrm{mM}$ of alkoxyamine functionality) was placed in an NMR tube fitted with a Young's tap. The tube was degassed with three freeze/pump/thaw cycles and closed under argon. The sealed tube was placed in the NMR cavity preheated to $125^{\circ} \mathrm{C}$. Spectra were recorded every $30 \mathrm{~min}$ for $16 \mathrm{~h}$. The three vinyl resonances of styrene at $\delta 6.74,5.77$, and $5.26 \mathrm{ppm}$ and the methine resonance of the alkoxyamine at approximately $\delta 4.9 \mathrm{ppm}$ were integrated and used to calculate the relative amounts of styrene (S) and alkoxyamine (A). The same procedure was repeated using TIPNO-based initiator $\mathbf{2}$ and TEMPO-based initiator $\mathbf{5}$. 


\section{General Polymerization Procedure}

A representative example is as follows: a mixture of $\mathrm{N}$-alkoxyamine $\mathbf{1}(18.9 \mathrm{mg}, 0.0291$ mmol, 1.00 equiv), styrene ( $2.0 \mathrm{~mL}, 17.46 \mathrm{mmol}, 600.0$ equiv: 300 equiv relative to moles of $N$-alkoxyamine functionality), and $0.5 \mathrm{~mL}$ of DMF was degassed in an ampule by three consecutive freeze-pump-thaw cycles and sealed under argon. In addition, bisnitroxide $\mathbf{3}$ was used in polymerizations with $t \mathrm{BA}, n \mathrm{BA}$, and DMA ( $0.6 \mathrm{mg}, 0.002 \mathrm{mmol}, 0.05$ equiv). The vial was heated to $70{ }^{\circ} \mathrm{C}$ until the solution became just slightly viscous, 7 days in this example. After cooling, a small aliquot was taken for a crude ${ }^{1} \mathrm{H}$ NMR spectrum to calculate percent conversion based on integration of the remaining monomer vs polymer peaks. For styrene, the integration from 6.9 to $6.3 \mathrm{ppm}$ (one dd representing $1 \mathrm{H}$ in the unreacted monomer and a broad peak representing $2 \mathrm{H}$ in the polymerized monomer) was compared to the integration from 5.9 to $5.2 \mathrm{ppm}$ (two dd, representing $2 \mathrm{H}$ in the unreacted monomer). A conversion of $45 \%$ was observed in this case. The remainder of the polymer sample was dissolved in a minimum amount of $\mathrm{CH}_{2}-\mathrm{Cl}_{2}$ (unless otherwise noted below), and the specified ice-chilled precipitation solvent $(6-10 \mathrm{~mL})$ was added dropwise. The resulting precipitated polymer was separated by decantation, and volatiles were removed in vacuo. This precipitation procedure was repeated two times to give $800 \mathrm{mg}$ of purified polymer which was analyzed by both ${ }^{1} \mathrm{H}$ NMR and GPC (number-average molecular weight $=M_{\mathrm{n}}=$ $34500 \mathrm{~g} / \mathrm{mol}$, polydispersity index $\left(M_{\mathrm{w}} / M_{\mathrm{n}}\right)=1.20$, where $M_{\mathrm{W}}=$ weight-average molecular weight). Polymers were precipitated as follows: polystyrene (PS) with methanol, poly(dimethylacrylamide) (PDMA) with hexanes, poly(tert-butyl acrylate) (PtBA) was dissolved in THF and precipitated with $50 \%$ aqueous methanol, and poly ( $n$-butyl acrylate) $(\mathrm{P} n \mathrm{BA})$ was dissolved in THF and precipitated with methanol.

\section{Time Studies}

For polymerization time studies, the desired amounts of initiator, monomer, and free nitroxide were combined to form a homogeneous solution. This mixture was divided evenly among several ampules, and each ampule was sealed under argon after three cycles of freeze-pump-thaw. The ampules were suspended simultaneously in a temperaturecontrolled oil bath and were removed after various time intervals. ${ }^{1} \mathrm{H}$ NMR spectra of aliquots of the crude polymerization mixtures were taken, and integration of the peaks was used to determine percent conversion and $[\mathrm{M}]_{0} /[\mathrm{M}]$, the ratio of the initial monomer concentration to the final monomer concentration. After precipitating the polymers, GPC was used to determine the number-average molecular weight $M_{\mathrm{n}, \mathrm{GPC}}$ and the polydispersity index, PDI.

\section{ABA Triblock Copolymers}

In a typical procedure, $50 \mathrm{mg}(0.012 \mathrm{mmol})$ of the $\mathrm{P} t \mathrm{BA}$ macroinitiator was combined with $0.500 \mathrm{~g}(4.80 \mathrm{mmol})$ of styrene in a $5 \mathrm{~mL}$ glass ampule. The ampule was sealed under argon after three cycles of freeze-pump-thaw. It was heated at $70{ }^{\circ} \mathrm{C}$ for 6 days. The resulting ABA triblock copolymer was dissolved in THF and precipitated with methanol $\left(M_{\mathrm{n}}=22\right.$ $400 \mathrm{~g} / \mathrm{mol}$, polydispersity index $\left.\left(M_{\mathrm{w}} / M_{\mathrm{n}}\right)=1.29\right)$.

\section{Sample Procedure for Thermal Decomposition}

A PS sample $\left(50.0 \mathrm{mg}, 0.0025 \mathrm{mmol}, M_{\mathrm{n}}=20300 \mathrm{~g} / \mathrm{mol}\right)$ was dissolved in $2 \mathrm{~mL}$ of $p$ xylene and heated to $130{ }^{\circ} \mathrm{C}$ for $16 \mathrm{~h}$ in a flask fitted with a septum with a needle open to air. The majority of the $p$-xylene was removed by vacuum distillation. GPC analysis of the concentrated sample gave $M_{\mathrm{n}}$ after cleavage $=11200 \mathrm{~g} / \mathrm{mol}$. 


\section{Results and Discussion}

\section{Low-Temperature Polymerization Studies}

Initial lower temperature studies were run with initiator 1 at $110{ }^{\circ} \mathrm{C}$ and $90{ }^{\circ} \mathrm{C}$ with styrene, tert-butyl acrylate, and $n$-butyl acrylate (Supporting Information). Polymerizations with acrylates and acrylamides were carried out with 5\% added free binitroxide $\mathbf{3}$ in order to ensure a sufficient concentration of the persistent nitroxide radical during the first moments of polymerization. ${ }^{4}$ Polydispersities less than 1.5 and good correlation between the molecular weights calculated from ${ }^{1} \mathrm{H}$ NMR integrations, $M_{\mathrm{n}, \mathrm{NMR}}$, and the experimental molecular weights measured by gel permeation chromatography, $M_{\mathrm{n}, \mathrm{GPC}}$, were observed for polymerization times of $3 \mathrm{~h}$ or longer. Following these successful results, polymerizations of styrene, tert-butyl acrylate, and dimethyl acrylamide were run at $70{ }^{\circ} \mathrm{C}$. The results are shown in Table 1.

These results at $70{ }^{\circ} \mathrm{C}$ provide evidence for "living" polymerizations. The polymerization of tert-butyl acrylate is a representative example. (Plots for the polymerization of all three monomers can be found in the Supporting Information.) A linear relationship exists between $\ln \left([\mathrm{M}]_{0} /[\mathrm{M}]\right)$ and time (Figure 2), indicating that there are no significant termination events during polymerization. In addition, the molecular weights based on ${ }^{1} \mathrm{H}$ NMR percent conversions and the experimental molecular weights obtained by GPC correlate well (Table 1 and Figure 3), suggesting an absence of chain transfer events. The polydispersity indices are very low for polystyrene (PDI $=1.18-1.30$ ); however, somewhat higher polydispersity indices are evident for both tert-butyl acrylate $(\mathrm{PDI}=1.54-1.64)$ and dimethylacrylamide $(\mathrm{PDI}=1.42-1.52)$.

A proof of "livingness" is the ability to add a second block. Thus, ABA triblock copolymers were prepared at $70{ }^{\circ} \mathrm{C}$ with bisalkoxyamine 1. GPC traces for one example are shown in Figure 4, where an internal B block of styrene was added to an A block macroinitiator of poly(tert-butyl acrylate) prepared at $70{ }^{\circ} \mathrm{C}$. There is an increase in molecular weight and a decrease in the polydispersity index of the resultant ABA triblock copolymer.

As demonstrated in the initial report of initiator $\mathbf{1},{ }^{47}$ monomer addition occurs at both ends of this symmetrical initiator. Bidirectional growth can be confirmed by several methods. ${ }^{52-}$ ${ }^{58}$ Because the final polymer contains a central bisnitroxide, thermolytic cleavage of the alkoxyamine $\mathrm{C}-\mathrm{O}$ bonds under conditions that result in nitroxide decomposition ${ }^{59}$ yield polymers of half the original molecular weight (Scheme 1). Presumably, the reaction occurs to form terminal olefins on the polymer chains and hydroxylamine functionalities on the bisnitroxide..$^{51,54,60}$ Under these reaction conditions, the hydroxylamines most likely undergo oxidation to nitroxides and further decomposition. ${ }^{59}$ Thus, polystyrene and poly(tert-butyl acrylate) samples prepared at 90 and $70{ }^{\circ} \mathrm{C}$ were heated to $130{ }^{\circ} \mathrm{C}$ in $p$ xylene overnight to effect cleavage at the center. The results of these thermolytic cleavage reactions confirm symmetrical bidirectional growth (Table 2). An example GPC trace is shown in Figure 5.

As a control, polymerizations with the parent monodirectional TIPNO initiator $\mathbf{2}$ were also investigated at $70{ }^{\circ} \mathrm{C}$ with styrene, tert-butyl acrylate, $n$-butyl acrylate, and dimethylacrylamide. The polymerization of styrene was successful. However the other monomers either underwent uncontrolled polymerization or with $5 \%$ added bisnitroxide did not undergo polymerization at all (Table 3).

\section{Dissociation Kinetics}

The ability of bidirectional initiator $\mathbf{1}$ to effect polymerization at lower temperatures than the parent initiator $\mathbf{2}$ motivated a detailed investigation of the kinetics of bond homolysis. 
Following the method of Fischer et al., ${ }^{50}$ the rate constants for the dissociation of bisalkoxyamine $\mathbf{1}$ and parent initiator $\mathbf{2}$ (Scheme 2) were compared at five different temperatures, ranging from 358 to $378 \mathrm{~K}$. Freshly synthesized alkoxyamine initiators $\mathbf{1}$ and 2 were used in this EPR investigation in order to ensure the purity of the samples. Oxygen was used as a radical scavenger, and tert-butylbenzene was used as the solvent. Because bisalkoxyamine $\mathbf{1}$ contains twice as many nitroxide moieties as parent initiator $\mathbf{2}$, a 0.601 $\mathrm{mM}$ solution of $\mathbf{1}$ was used, compared to a $1.20 \mathrm{mM}$ solution of $\mathbf{2}$. In this way, the concentration of alkoxyamine functionalities was $1.20 \mathrm{mM}$ in both samples. The nitroxides which form during these homolysis experiments decompose at high temperatures; $; 9$ therefore, the stable nitroxide TEMPO was used as a calibration standard to convert the second integral of the EPR signal into nitroxide concentration.

As a typical example, Figure 6 shows the concentration of nitroxide vs time when samples of bisalkoxyamine $\mathbf{1}$ and parent alkoxyamine $\mathbf{2}$ were heated at $363 \mathrm{~K}$ for $1 \mathrm{~h}$. The $\mathrm{C}-\mathrm{O}$ bond homolysis of bisalkoxyamine $\mathbf{1}$ is significantly faster than that of parent alkoxyamine $\mathbf{2}$. Similar results were seen at $358,368,373$, and $378 \mathrm{~K}$ (see Supporting Information).

Because the nitroxide that forms during this homolysis undergoes further decomposition, the value of the rate constant $k_{\mathrm{d}}$ was calculated from the initial slope of the graph of nitroxide concentration vs time:

$$
k_{\mathrm{d}}=\frac{\left(\frac{\mathrm{d}[\mathrm{N}]}{\mathrm{d} t}\right)_{t=0}}{[\mathrm{~A}]_{0}}
$$

where $[N]$ is the concentration of nitroxide functionality and $[A]_{0}$ is the initial concentration of alkoxyamine functionality. The derivation of eq 1 for a bisalkoxyamine is given in the Supporting Information.

The calculated rate constants $\left(k_{\mathrm{d}}\right)$, activation energies $\left(E_{\mathrm{a}}\right)$, and pre-exponential factors $(A)$ of $\mathbf{1}$ and $\mathbf{2}$ are shown in Table 4 along with the literature values for the parent TIPNO initiator $\mathbf{2}$. The calculated $k_{\mathrm{d}}$ values for $\mathbf{2}$ agree well with the literature values. The calculated activation energies and Arrhenius parameters are very sensitive to temperature. A difference of $1 \mathrm{~K}$ in the measured temperature can cause a difference of $5 \mathrm{~kJ} / \mathrm{mol}$ in the calculated $E_{\mathrm{A}}$ and a factor of 10 difference in $A$. This might explain the discrepancy between the calculated $E_{\mathrm{A}}$ and $A$ values for $\mathbf{2}$ and the literature values. Thus, caution must be used when comparing values measured by different researchers. As seen in Table 4, the dissociation rate constants for bisalkoxyamine $\mathbf{1}$ are about twice as large as those for parent alkoxyamine $\mathbf{2}$ in the temperature range studied. This increased rate of $\mathrm{C}-\mathrm{O}$ bond homolysis contributes to the ability of bisalkoxyamine initiator $\mathbf{1}$ to mediate polymerizations at faster rates and lower temperatures than parent initiator 2 . Fischer has shown through kinetic analysis that the polymerization time of NMRP decreases with increasing $k_{\mathrm{d}}$, and control is maintained as long as $k_{\mathrm{d}}$ does not become too large (about $10^{-1} \mathrm{~s}^{-1}$ ). ${ }^{61}$ The improved polymerization capabilities of alkoxyamines with acyclic nitroxides such as TIPNO and SG1 have been attributed in part to their higher $k_{\mathrm{d}}$ values $\left(\sim 10^{-3} \mathrm{~s}^{-1}\right)$ compared to TEMPO-based alkoxyamines $\left(\sim 10^{-4} \mathrm{~s}^{-1}\right) .{ }^{50}$ Using the measured values of $E_{\mathrm{a}}$ and $A$ and extrapolating to $120^{\circ} \mathrm{C}$ gives dissociation rate constants of $5.2 \times 10^{-3}$ and $2.7 \times 10^{-3} \mathrm{~s}^{-1}$ for alkoxyamines $\mathbf{1}$ and $\mathbf{2}$, respectively. The value for $\mathbf{1}$ is larger than many values found in the literature ${ }^{31,50}$ but not too large for the polymerization to lose control. 


\section{${ }^{1} \mathrm{H}$ NMR Alkoxyamine Decomposition Studies}

The relative rates of decomposition of bisalkoxyamine $\mathbf{1}$ and parent initiator $\mathbf{2}$ in the absence of monomer were determined by the method of Fukuda et al. ${ }^{62}$ In order to try to simulate the conditions during polymerization, each alkoxyamine was heated in the absence of molecular oxygen. Repeated homolysis and recombination ensues, with eventual decomposition to form styrene and hydroxylamine (Scheme 3). ${ }^{63}$

The pseudo-first-order integrated rate law for this decomposition is given by eq 2 :

$$
\ln \left(\frac{[\mathrm{A}]+[\mathrm{S}]}{[\mathrm{A}]}\right)=k_{\mathrm{dec}} t
$$

As shown by Fukuda, ${ }^{62,64}$ the rate constant $k_{\mathrm{dec}}$ may be expressed as

$$
k_{\mathrm{dec}}=p_{\mathrm{dec}} k_{\mathrm{d}}
$$

where $p_{\mathrm{dec}}$ is the probability of decomposition. This equation accounts for the fact that faster rates of homolysis can lead to faster apparent rates of decomposition. Because the decomposition of alkoxyamines into hydroxylamines and alkenes can lead to incomplete monomer conversions and high polydisperisties, ${ }^{65}$ smaller $p_{\text {dec }}$ values are desirable in alkoxyamine initiators.

This reaction is conveniently monitored by ${ }^{1} \mathrm{H}$ NMR spectroscopy by integration of the signals corresponding to the vinylic hydrogens of styrene and the alkoxyamine methine proton at $\delta 4.90\left(\mathrm{CH}_{3} \mathrm{CHO}\right)$ to give the relative amounts of styrene, $\mathrm{S}$, and alkoxyamine, A. Because bisalkoxyamine $\mathbf{1}$ contains twice as many nitroxide moieties as parent initiator $\mathbf{2}$, a $90 \mathrm{mM}$ solution of $\mathbf{1}$ was used, as compared to a $180 \mathrm{mM}$ solution of $\mathbf{2}$. In this way, the concentration of alkoxyamine functionality was $180 \mathrm{mM}$ in both samples.

Figure 7 shows the disappearance of the alkoxyamine functionality and the evolution of styrene for bisalkoxyamine $\mathbf{1}$ and parent alkoxyamine $\mathbf{2}$ at $125^{\circ} \mathrm{C}$. For both $\mathbf{1}$ and $\mathbf{2}$, the decrease in alkoxyamine concentration appears to occur more rapidly than the increase in styrene concentration. The total concentration of alkoxyamine and styrene, $[\mathrm{A}]+[\mathrm{S}]$, does not remain constant. This may indicate that either (1) the alkoxyamine decomposes through an additional mechanism that does not result in the formation of styrene or (2) the styrene that forms undergoes an additional reaction, such as polymerization. No broad polymer peaks were detected in the region 6.2-7.4 ppm in the ${ }^{1} \mathrm{H}$ NMR spectra, indicating that no significant polymerization occurs under these dilute conditions. Analogous decomposition studies using the TEMPO-derived alkoxyamine $\mathbf{5}$ showed a similar deficit in the mass balance (Supporting Information). However, this apparent loss of material was not reported by Fukuda, et al. ${ }^{62}$ or Fischer et al., ${ }^{60}$ who also studied the decomposition of $\mathbf{5}$. The results in Figure 7 were reproducible, even at different alkoxyamine concentrations (Supporting Information) and extended $T_{1}$ relaxation times; thus, the possibility of an alternate decomposition pathway cannot be ruled out.

The kinetics of these decomposition reactions were further analyzed by plotting $\ln ([\mathrm{A}]+$ $[\mathrm{S}]$ )/[A]) as a function of time (Figure 8, eq 2). If the decompositions are first-order or pseudo-first-order, this plot will be linear. This is the case for parent alkoxyamine $\mathbf{2}$ and for TEMPO-based initiator 5. Slopes of the best fit lines give $k_{\mathrm{dec}}$ values of $3.7 \times 10^{-6}$ and $1.6 \times$ $10^{-5} \mathrm{~s}^{-1}$ for $\mathbf{2}$ and $\mathbf{5}$, respectively. The $k_{\mathrm{dec}}$ value for $\mathbf{2}$ was the same at initial alkoxyamine 
concentrations of 90 and $180 \mathrm{mM}$. The value for 5 correlates well with the literature value of $k_{\mathrm{dec}}=4.5 \times 10^{-5} \mathrm{~s}^{-1}$ at $140{ }^{\circ} \mathrm{C}$ determined by Fukuda and co-workers. ${ }^{62}$ However, as is evident in Figure 8, the relationship between $\ln ([\mathrm{A}]+[\mathrm{S}]) /[\mathrm{A}])$ and time for initiator $\mathbf{1}$ is not linear. This experiment with initiator 1 was repeated with extended $T_{1}$ relaxation times (original $T_{1}=1 \mathrm{~s}$ ) of 10 and $15 \mathrm{~s}$ with no significant change, indicating that the nonlinearity is not a result of increased molecular relaxation times resulting from the absence of molecular oxygen or the increase in temperature. ${ }^{66}$ The curvature in this plot suggests an alternate decomposition pathway for alkoxyamine $\mathbf{1}$ (or bisnitroxide $\mathbf{3}$ ), rather than the simple mechanism shown in Scheme 3.

The rate of decomposition of alkoxyamine into hydroxylamine and styrene can be quantified by looking at the rate of formation of styrene, rather than the disappearance of alkoxyamine. This avoids the complication of alkoxyamine decomposition through a different mechanism. An alternative expression of the integrated rate law is

$$
\ln \left(\frac{[\mathrm{A}]_{0}}{[\mathrm{~A}]_{0}-[\mathrm{S}]}\right)=k_{\mathrm{dec}} t
$$

and a plot of this relationship for alkoxyamines $\mathbf{1}$ and $\mathbf{2}$ is shown in Figure 9 . For both alkoxyamines $\mathbf{1}$ and $\mathbf{2}$, this relationship is linear, and slopes of the best-fit lines give $k_{\mathrm{dec}}$ values of $5.2 \times 10^{-6}$ and $2.8 \times 10^{-6} \mathrm{~s}^{-1}$, respectively. This $k_{\mathrm{dec}}$ value for $\mathbf{2}$ is close to the previous value found from eq 2 and Figure 8. Using the measured values of $E_{\mathrm{a}}$ and $A, k_{\mathrm{d}}$ at $125^{\circ} \mathrm{C}$ was calculated, and eq 3 was used to determine the probability of decomposition $p_{\mathrm{dec}}$ (Table 5). These results show that bisalkoxyamine $\mathbf{1}$ is no more likely to decompose into hydroxylamine and styrene than parent alkoxyamine 2 . Their estimated $p_{\text {dec }}$ values are both on the order of magnitude of $10^{-4}$. In contrast, TEMPO-based alkoxyamine 5 has a $p_{\text {dec }}$ value near $10^{-2}$, making it $\sim 40$ times more likely to decompose to styrene and hydroxylamine, as shown in Scheme 3.

\section{EPR Nitroxide Decomposition Studies}

The curvature of the plot for bisalkoxaymine 1 in Figure 8 suggests that the decomposition pathway for this species is enhanced. Decomposition to form hydroxylamine and styrene as depicted in Scheme 3 is not the only mode of nitroxide decomposition (Scheme 4). $\alpha$ Hydrogen bearing nitroxides work well in nitroxide-mediated radical polymerization specifically because of their ability to undergo bimolecular decomposition ${ }^{59,67}$ at polymerization temperatures, keeping the concentration of the free nitroxide low. Fischer has shown kinetically that the rate of polymerization can be enhanced by the decay of the persistent radical without adversely affecting the polydispersity or control of the molecular weight. ${ }^{68}$ Additives that cause nitroxide decomposition ${ }^{3}$ and persistent radicals with built-in decomposition pathways ${ }^{69}$ have both been used to increase polymerization rates under controlled conditions. As long as nitroxide decomposition does not simultaneously create a "dead" chain (as occurs with hydroxylamine and alkene formation), the concentration of the persistent radical will remain low enough to allow higher monomer conversions in less time.

The relative rates of decomposition of bisnitroxide $\mathbf{3}$, TIPNO mononitroxide $\mathbf{4}$, and TEMPO were investigated using EPR. Freshly synthesized nitroxide samples in tert-butylbenzene were heated at $120^{\circ} \mathrm{C}$, and the change in nitroxide concentration with time was measured. Because one molecule of bisnitroxide 3 contains two nitroxide moieties, a $2.02 \mathrm{mM}$ solution of $\mathbf{3}$ was used, compared to $4.03 \mathrm{mM}$ solutions of $\mathbf{4}$ and TEMPO. In this way, the concentration of nitroxide functionality was $4.0 \mathrm{mM}$ in all samples. As with the homolysis experiments, TEMPO was used as a calibration standard to convert the EPR signal into 
nitroxide concentration. Figure 10 shows the concentration of nitroxide vs time when samples of bisnitroxide 3, mononitroxide 4, and TEMPO were heated at $120{ }^{\circ} \mathrm{C}$ for $2 \mathrm{~h}$. As expected, the stable nitroxide TEMPO does not decompose at $120^{\circ} \mathrm{C}$ : its concentration remains $4.0 \mathrm{mM}$ throughout the experiment. In contrast, both nitroxides $\mathbf{3}$ and $\mathbf{4}$ undergo an overall decrease in concentration when heated. Bisnitroxide $\mathbf{3}$ decomposes almost completely within $1 \mathrm{~h}$, while only $20 \%$ of mononitroxide 4 decomposes within the same amount of time. Although the decomposition kinetics do not follow a simple first- or second-order rate law, it is evident that bisnitroxide $\mathbf{3}$ decomposes at a much faster rate than mononitroxide 4. Similar results were obtained when the experiment was repeated at 2.0 $\mathrm{mM}$ nitroxide concentration (Supporting Information).

An unusual feature of these decomposition experiments is that the initial concentration of nitroxide, as measured by EPR, is not equal to $4.0 \mathrm{mM}$. For mononitroxide 4, this effect is small: the initial measured concentration is $3.9 \mathrm{mM}$. However, for bisnitroxide $\mathbf{3}$, the initial measured concentration is only $1.0 \mathrm{mM}$. This difference in concentration is too large to be the result of experimental error. As bisnitroxide $\mathbf{3}$ was heated, its concentration increased from 1.0 to $1.8 \mathrm{mM}$ before beginning to decrease. This unusual behavior is reproducible; a separately synthesized sample of bisnitroxide $\mathbf{3}$ gave nearly identical results (Supporting Information). We hypothesize that some of the nitroxide may have converted to hydroxylamine prior to running the EPR experiment. Upon heating in the presence of air, the hydroxylamine is oxidized back to nitroxide. This would explain the low concentration of nitroxide at the beginning of the experiment as well as the initial increase in concentration during the first $15 \mathrm{~min}$. The nitroxide concentration of $\mathbf{3}$ never reaches $4.0 \mathrm{mM}$ because it decomposes at the same time that it is being formed. Nevertheless, even with a smaller initial concentration, bisnitroxide $\mathbf{3}$ decomposes more rapidly than parent nitroxide $\mathbf{4}$.

This experiment does not simulate polymerization conditions. All EPR samples were exposed to air, and nitroxide concentrations were somewhat higher than those found in a typical polymerization. Attempts to repeat this experiment in the absence of oxygen (by performing freeze-pump-thaw on the EPR samples) led to nonreproducible results. This may be due to the inability to completely remove all of the oxygen from the sample. Nitroxide concentrations on the order of $1-10^{-2} \mathrm{mM}$, which would more closely mimic polymerization conditions, ${ }^{70,71}$ are more difficult to detect accurately by EPR.

The enhanced decomposition of bisnitroxide $\mathbf{3}$ may result from an intramolecular disproportionation reaction by single electron $\operatorname{transfer}^{59}$ in the rare event that the bisnitroxide is formed at elevated temperatures. Formation of bisnitroxide $\mathbf{3}$ during the polymerization is expected to be more significant at extended polymerization times. Regardless of the mechanism of decomposition, bisnitroxide $\mathbf{3}$ decomposes faster than parent nitroxide $\mathbf{4}$, and this may contribute to the enhanced rates of polymerization observed for initiator $\mathbf{1}$.

\section{Low-Temperature EPR Studies}

Both bisnitroxide 3 and mononitroxide $\mathbf{4}$ were examined at low-temperature by EPR. ${ }^{72}$

Bisnitroxide $\mathbf{3}$ shows a strong interaction at low-temperature, indicating that the conformation holds both nitroxide moieties close in space. An indication of strong biradical dipolar coupling is a half-field absorption signal as well as line broadening at the full field absorption line shape. ${ }^{73-75}$ When two radical spins are held in close proximity, the normally forbidden transition $(\Delta m=2)$ becomes allowed and observable in the half-field region. The integration of this signal normalized against spin concentration correlates to the interspin distance through the relationship of $1 / r^{6} .{ }^{73}$ Figure 11 shows the EPR spectra of $\mathbf{3}$ and $\mathbf{4}$. As expected, only bisnitroxide $\mathbf{3}$ exhibited a half field signal. The relative intensity (adjusted for 
difference in microwave power) is $3.2 \times 10^{-3}$ : using eq 5 , the nitroxide-nitroxide distance is $4.7 \AA$.

$$
\text { relative intensity }=\frac{A}{r^{6}}\left(\frac{9.1}{v}\right)^{2}
$$

where $A=19.5$ for organic radicals, $r$ is the interspin distance in angstroms, and $v$ is the spectrometer frequency in $\mathrm{GHz}$.

In addition to the appearance of a half-field signal, dipolar coupling is also revealed by the line shape of the full field EPR spectrum. In the absence of angular correlation between the dipolar tensor and the nitroxide magnetic tensors, the overall line shape can be expressed as the convolution of the EPR spectrum of an isolated spin with a dipolar spectral function. The peak-to-peak width of the dipolar broadening function provides an alternate method to calculate the interspin distance, as given by eqs 6 and $7 .^{75}$ The dipolar broadening function was determined by deconvolution of the spectrum of bisnitroxide $\mathbf{3}$ with the spectrum of the mononitroxide TIPNO 4 (representative of an isolated spin). The Fourier transform method of Rabenstein and $\mathrm{Shin}^{76}$ was employed, with the addition of a regularization parameter to limit noise. The resulting broadening function is shown in Figure 12. The majority of the broadening function conforms to the expected "Pake pattern" that results from a pair of spins with strong dipolar coupling, superimposed with two much narrower functions whose structures cannot be resolved. Lack of resolution may result from the smoothing effects of noise suppression, distance distributions, or other factors; however, these narrower broadening functions often conform to a Gaussian line shape. ${ }^{77}$ The fwhm (full width at half-maximum) of this Gaussian function can then be used to calculate a distance using eq $6 .{ }^{78}$

$$
r=\sqrt[3]{\frac{1.95 \times 10^{4}}{B}}
$$

where $B$ is the Gaussian fwhm in $\mathrm{G}$ and $r$ the distance in $\AA$.

The broadening function could only be well fit with a minimum of three separate functions, each of which corresponds to a population with different interspin distances. The three functions are also shown in Figure 12, with their sum superimposed on the dipolar broadening function. In addition, this simulated broadening function was convoluted with the EPR spectrum of mononitroxide $\mathbf{4}$ to yield a simulated spectrum of the bisnitroxide $\mathbf{3}$, shown in Figure 13. The details of the three broadening functions are as follows: first, the narrow central spike was fit with a Gaussian of width $2.25 \mathrm{G}$. This would be derived from an interspin distance of over $20 \AA$ (eq 6) and is most likely from a small amount (9\%) of monoradical impurity, arising from either the incomplete oxidation of both nitroxides during synthesis or the decomposition of one over time. The next part of the broadening function was simulated with a 20 G Gaussian function. This corresponds to a distance of $9.8 \AA$ (eq 6) and is representative of a population (30\%) of the bisnitroxide with the two spins at a maximum separation, as depicted by structure $\mathbf{6}$ (Figure 14). The majority of the broadening function (61\%) is well fit with a "Pake pattern" with a width of $150 \mathrm{G}$ between the inner turning points and represents the two spins in close proximity, as depicted by structure 7 (Figure 14). Employing eq 7, a distance of $5.8 \AA$ is calculated. 


$$
2 B_{\text {pake }}=\frac{3}{2} \frac{g^{2} \beta^{2}}{r^{2}}
$$

where $2 B_{\text {pake }}$ is the distance between inner turning points in $\mathrm{G}, g$ is the $g$-factor $=2$ for nitroxides, $B^{2}=4635 \mathrm{G} / \AA^{3}$, and $r$ is the distance in $\AA$.

The interspin distances calculated from the half-field method and the deconvolution method corroborate the interaction of the two nitroxides. Previous studies have shown that when both techniques are applied to the same system, the half-field method predicts a shorter interspin distance than deconvolution methods. ${ }^{79}$ One reason for this is that the half-field signal increases in amplitude with closer distances, while the full field signal broadens (but retains the same area) and decreases in amplitude. Therefore, taken together, these two methods describe a majority population with an inter-spin distance in the range of 4.7-5.8 and a smaller population with a distance in the $9-10 \AA$ range.

\section{Implications toward Polymerization}

The characteristics of $\mathbf{1}$ in NMRP cannot be explained by existing effects involving single nitroxides. For example, earlier work from this $1 \mathrm{ab}^{48}$ showed that macroinitiator 8 (Figure 15 ), which is sterically similar to the alkoxyamine formed from $\mathbf{1}$ during polymerization, effects NMRP at the same rate as the monodirectional initiator $\mathbf{2}$. Similarly, the sterically hindered alkoxyamine 9 (Figure 15) developed by Studer ${ }^{31}$ effects polymerization of both styrene and $n$-butyl acrylate more slowly than bisinitiator $\mathbf{1}$. Thus, it is clear that neither slow diffusion due to the polymeric nature of the nitroxide nor steric congestion around the nitroxide can explain the enhanced rate of homolysis of initiator $\mathbf{1}$.

The EPR data show that $\sim 61 \%$ of the bisnitroxide exists in a state in which there is significant spin-spin interaction. The bisnitroxide is a mixture of two inseparable diastereomers. It is likely that one diastereomer experiences a closer spin-spin interaction that the other. To account for the unusually short nitroxide-nitroxide distance, a chairlike conformation 7 enhanced by two Thorpe-Ingold gem-dimethyl effects ${ }^{80}$ places the two nitroxide groups in close proximity. The other diastereomer may adopt an extended conformation 6, in which the nitroxide groups are remote. This correlates with the two nitroxide interspin distances of approximately 5.8 and $9.8 \AA$ derived from the EPR measurements.

The close proximity of the two nitroxide moieties in bisnitroxide $\mathbf{3}$ may explain the faster rates of $\mathrm{C}-\mathrm{O}$ bond homolysis and nitroxide decomposition of bisalkoxyamine $\mathbf{1}$ as compared to parent alkoxyamine $\mathbf{2}$. We propose that during polymerization, homolysis of the $\mathrm{C}-\mathrm{O}$ bond is facilitated by stabilization of the resulting mononitroxide through a synergistic interaction from the adjacent $\mathrm{N}$-alkoxyamine. The resulting mixed nitroxide and $\mathrm{N}$ alkoxyamine species 10 (Figure 16) resides in a chairlike conformation where the two N-O moieties are held in close proximity. Resonance structures 10, 11, and $\mathbf{1 2}$ can be drawn in which the active carbon of the remaining polymer chain is bonded to either $\mathrm{N}-\mathrm{O}$ group. This radical can therefore be thought of as being delocalized over five atoms (including the two nitrogen atoms), as depicted in resonance hybrid 13, with the polymer chain being shared equally between both partial nitroxides. This stabilization would lead to a higher $k_{\mathrm{d}}$ for $\mathrm{C}-\mathrm{O}$ bond homolysis, in agreement with the experimental findings presented herein. The near proximity of the nitroxide moieties may also explain the increased rate of nitroxide decomposition. An intramolecular decomposition pathway would lead to faster rates of decomposition, as was observed in the EPR experiments. 
This proposed nitroxide resonance stabilization implies that dissociation of the first nitroxide from the bisalkoxyamine occurs more easily than dissociation of the second nitroxide. Thus, the $k_{\mathrm{d}}$ values in Table 4 refer to the dissociation of the first nitroxide moiety, since the initial slope method (eq 1) was used to calculate $k_{\mathrm{d}}$ (see Supporting Information for a detailed derivation).

This unprecedented mode of stabilization suggests a new strategy for the design of nitroxides for use in low-temperature NMRP in which bisnitroxides are conformationally biased or covalently restricted to reside in close proximity. Work along these lines as well as other applications of this strongly interacting bisnitroxide are currently under investigation.

\section{Conclusion}

Bidirectional initiator 1 effects the polymerization of styrene, tert-butyl acrylate, $n$-butyl acrylate, and dimethylacrylamide at temperatures as low as $70{ }^{\circ} \mathrm{C}$. The ability to effect NMRP at temperatures $\sim 50^{\circ} \mathrm{C}$ lower than those commonly employed will extend NMRP to applications involving biomolecules and other heat sensitive substrates. Kinetic studies reveal bidirectional initiator $\mathbf{1}$ undergoes homolytic cleavage $\sim 2$ times faster that monodirectional initiator $\mathbf{2}$. When heated in the absence of oxygen, both $\mathbf{1}$ and $\mathbf{2}$ are equally likely to decompose into hydroxylamine and styrene; however, bidirectional initiator $\mathbf{1}$ exhibits an accelerated decomposition, as seen dramatically in Figure 8. EPR studies similarly show that bisnitroxide $\mathbf{3}$ decomposes faster than TIPNO nitroxide 4 . Lowtemperature EPR studies indicate a striking spin-spin interaction for bisnitroxide $\mathbf{3}$. Chairlike conformation $\mathbf{7}$ enhanced by two Thorpe-Ingold gem-dimethyl interactions is proposed to impart conformational constraints facilitating this unusually strong spin-spin interaction. The near proximity of the nitroxide moieties apparently leads to an enhanced rate of bond homolysis and thus allows bisalkoxyamine 1 to effect controlled polymerizations at temperatures as low as $70^{\circ} \mathrm{C}$. A new class of proximal bisnitroxides can be envisioned for future advances in NMRP.

\section{Supplementary Material}

Refer to Web version on PubMed Central for supplementary material.

\section{Acknowledgments}

The authors thank Research Corporation (RA0336) for financial support in addition to equipment grants from the NSF (CHE-0342912) (NMR) and DBI-0217922 (to G.M.) and grants from NIH (CA52955) (ESITOFMS) and (GM 65790, to G.M.). J.R. thanks NSF for a Graduate Research Fellowship. We are also grateful to C. Bernasconi for helpful discussions on kinetics and $\mathrm{H}$. Ito for suggested ${ }^{1} \mathrm{H}$ NMR experiments.

\section{References and Notes}

1. Hawker CJ, Bosman AW, Harth E. Chem Rev. 2001; 101:3661-3688. [PubMed: 11740918]

2. Solomon, DH.; Rizzardo, E.; Cacioli, P. Eur Pat Appl. 135280. 1985.

3. Georges MK, Veregin RPN, Kazmaier PM, Hamer GK, Saban M. Macromolecules. 1994; 27:72287229.

4. Benoit D, Chaplinski V, Braslau R, Hawker CJ. J Am Chem Soc. 1999; 121:3904-3920.

5. Benoit D, Grimaldi S, Robin S, Finet JP, Tordo P, Gnanou Y. J Am Chem Soc. 2000; 122:5929_ 5939.

6. Pintauer T, Matyjaszewski K. Coord Chem Rev. 2005; 249:1155-1184.

7. Matyjaszewski K, Xia JH. Chem Rev. 2001; 101:2921-2990. [PubMed: 11749397]

8. Kamigaito M, Ando T, Sawamoto M. Chem Rev. 2001; 101:3689-3745. [PubMed: 11740919] 
9. Patten TE, Xia JH, Abernathy T, Matyjaszewski K. Science. 1996; 272:866-868. [PubMed: 8662578]

10. Kato M, Kamigaito M, Sawamoto M, Higashimura T. Macromolecules. 1995; 28:1721-1723.

11. Percec V, Barboiu B. Macromolecules. 1995; 28:7970-7972.

12. Granel C, Dubois P, Jerome R, Teyssie P. Macromolecules. 1996; 29:8576-8582.

13. Wayland BB, Basickes L, Mukerjee S, Wei ML, Fryd M. Macromolecules. 1997; 30:8109-8112.

14. Ando T, Kamigaito M, Sawamoto M. Macromolecules. 1998; 31:6708-6711.

15. Collins JE, Fraser CL. Macromolecules. 1998; 31:6715-6717.

16. Percec V, Barboiu B, van der Sluis M. Macromolecules. 1998; 31:4053-4056.

17. Moineau G, Granel C, Dubois P, Jerome R, Teyssie P. Macromolecules. 1998; 31:542-544.

18. Moad G, Rizzardo E, Thang SH. Aust J Chem. 2005; 58:379-410.

19. Lowe AB, McCormick CL. Prog Polym Sci. 2007; 32:283-351.

20. Chiefari J, Chong YK, Ercole F, Krstina J, Jeffery J, Le TPT, Mayadunne RTA, Meijs GF, Moad CL, Moad G, Rizzardo E, Thang SH. Macromolecules. 1998; 31:5559-5562.

21. Mayadunne RTA, Rizzardo E, Chiefari J, Krstina J, Moad G, Postma A, Thang SH. Macromolecules. 2000; 33:243-245.

22. Mayadunne RTA, Rizzardo E, Chiefari J, Chong YK, Moad G, Thang SH. Macromolecules. 1999; 32:6977-6980.

23. Perrier S, Takolpuckdee P. J Polym Sci, Part A: Polym Chem. 2005; 43:5347-5393.

24. Barner-Kowollik C, Buback M, Charleux B, Coote ML, Drache M, Fukuda T, Goto A, Klumperman B, Lowe AB, McLeary JB, Moad G, Monteiro MJ, Sanderson RD, Tonge MP, Vana P. J Polym Sci, Part A: Polym Chem. 2006; 44:5809-5831.

25. For one example, see: Bosman AW, Vestberg R, Heumann A, Frechet JMJ, Hawker CJ. J Am Chem Soc. 2003; 2125:2715-2728.

26. Solomon DH. J Polym Sci, Part A: Polym Chem. 2005; 43:5748-5764.

27. Shipp DA. J Macromol Sci, Polym Rev. 2005; C45:171-194.

28. Braunecker WA, Matyjaszewski K. Prog Polym Sci. 2007; 32:93-146.

29. Qiu J, Charleux B, Matyjaszewski K. Prog Polym Sci. 2001; 26:2083-2134.

30. Rodlert M, Harth E, Rees I, Hawker CJ. J Polym Sci, Part A: Polym Chem. 2000; 38:4749-4763.

31. Studer A, Harms K, Knoop C, Muller C, Schulte T. Macromolecules. 2004; 37:27-34.

32. Lagrille O, Cameron NR, Lovell PA, Blanchard R, Goeta AE, Koch R. J Polym Sci, Part A: Polym Chem. 2006; 44:1926-1940.

33. Detrembleur C, Sciannamea V, Koulic C, Claes M, Hoebeke M, Jerome R. Macromolecules. 2002; 35:7214-7223.

34. Sciannamea V, Guerrero-Sanchez A, Schubert US, Catala JM, Jerome R, Detrembleur C. Polymer. 2005; 46:9632-9641.

35. Detrembleur C, Teyssie P, Jerome R. Macromolecules. 2002; 35:1611-1621.

36. Drockenmuller E, Catala JM. Macromolecules. 2002; 35:2461-2466.

37. Drockenmuller E, Lamps JP, Catala JM. Macromolecules. 2004; 37:2076-2083.

38. Harth E, van Horn B, Hawker CJ. Chem Commun. 2001:823-824.

39. Studer A. Angew Chem, Int Ed. 2000; 39:1108-1111.

40. Schulte T, Studer A. Macromolecules. 2003; 36:3078-3084.

41. Knoop CA, Studer A. J Am Chem Soc. 2003; 125:16327-16333. [PubMed: 14692774]

42. Wetter C, Gierlich J, Knoop CA, Muller C, Schulte T, Studer A. Chem- Eur J. 2004; 10:11561166.

43. Siegenthaler KO, Studer A. Macromolecules. 2006; 39:1347-1352.

44. Dire C, Charleux B, Magnet S, Couvreur L. Macromolecules. 2007; 40:1897-1903.

45. Nicolas J, Dire C, Mueller L, Belleney J, Charleux B, Marque SRA, Bertin D, Magnet S, Couvreur L. Macromolecules. 2006; 39:8274-8282.

46. Guillaneuf Y, Gigmes D, Marque SRA, Astolfi P, Greci L, Tordo P, Bertin D. Macromolecules. 2007; 40:3108-3114. 
47. Hill NL, Braslau R. Macromolecules. 2005; 38:9066-9074.

48. Ruehl J, Braslau R. J Polym Sci, Part A: Polym Chem. 2007; 45:2015-2025.

49. Braslau R, Tsimelzon A, Gewandter J. Org Lett. 2004; 6:2233-2235. [PubMed: 15200328]

50. Marque S, Le Mercier C, Tordo P, Fischer H. Macromolecules. 2000; 33:4403-4410.

51. Huang WL, Chiarelli R, Charleux B, Rassat A, Vairon JP. Macromolecules. 2002; 35:2305-2317.

52. Higaki Y, Otsuka H, Takahara A. Macromolecules. 2004; 37:1696-1701.

53. Hawker CJ, Barclay GG, Dao JL. J Am Chem Soc. 1996; 118:11467-11471.

54. Lizotte JR, Anderson SG, Long TE. J Polym Sci, Part A: Polym Chem. 2004; 42:1547-1556.

55. Buston JEH, Coldham I, Mulholland KR. J Chem Soc Perkin Trans. 1999; 1:2327-2334.

56. Liu YB, Maden A, Murray WV. Tetrahedron. 2002; 58:3159-3170.

57. O’Bryan G, Braslau R. Macromolecules. 2006; 39:9010-9017.

58. Lee S, Zhao ZS. Tetrahedron Lett. 1999; 40:7921-7924.

59. Nilsen A, Braslau R. J Polym Sci, Part A: Polym Chem. 2006; 44:697-717.

60. Ananchenko GS, Fischer H. J Polym Sci, Part A: Polym Chem. 2001; 39:3604-3621.

61. Fischer H. Macromolecules. 1997; 30:5666-5672.

62. Goto A, Kwak Y, Yoshikawa C, Tsujii Y, Sugiura Y, Fukuda T. Macromolecules. 2002; 35:35203525.

63. It should be noted that the mechanism of decomposition may not go through the homolytic cleavage shown in Scheme 2. Alternative mechanisms, particularly for ester functionalized initiators, cannot be ruled out, such as nonradical ionic elimination or a concerted mechanism. For phenethyl-functionalized initiators, however, most evidence is in support of radical intermediates. 63,67

64. Ohno K, Tsujii Y, Fukuda T. Macromolecules. 1997; 30:2503-2506.

65. Souaille M, Fischer H. Macromolecules. 2001; 34:2830-2838.

66. Ito H, Dalby C, Pomerantz A, Sherwood M, Sato R, Sooriyakumaran R, Guy K, Breyta G. Macromolecules. 2000; 33:5080-5089.

67. Bowman DF, Gillan T, Ingold KU. J Am Chem Soc. 1971; 93:6555-6561.

68. Souaille M, Fischer H. Macromolecules. 2002; 35:248-261.

69. Steenbock M, Klapper M, Mullen K. Acta Polym. 1998; 49:376-378.

70. Fukuda T, Terauchi T, Goto A, Ohno K, Tsujii Y, Miyamoto T, Kobatake S, Yamada B. Macromolecules. 1996; 29:6393-6398.

71. Fischer H. J Polym Sci, Part A: Polym Chem. 1999; 37:1885-1901.

72. For an extensive database of bisnitroxides and the EPR spectra see: Organic Cation Radicals and Polyradicals. Index of Substances for Volumes II/1 and II/9, Landolt-Börnstein - Group II Molecules and Radicals. Vol. 9d2. Springer-Verlag; Berlin: 1980.

73. Eaton SS, Eaton GR. J Am Chem Soc. 1982; 104:5002-5003.

74. van der Waals JH, de Groot MS. Mol Phys. 1959; 2:333-340.

75. Slichter, CP. Principles of Magnetic Resonance. 3. Springer-Verlag; New York: 1996. p. 669

76. Rabenstein MD, Shin YK. Proc Natl Acad Sci USA. 1995; 92:8239-8243. [PubMed: 7667275]

77. Ottemann KM, Thorgeirsson TE, Kolodziej AF, Shin YK, Koshland DE. Biochemistry. 1998; 37:7062-7069. [PubMed: 9585515]

78. Walter ED, Sebby KB, Usselman RJ, Singel DJ, Cloninger MJ. J Phys Chem B. 2005; 109:2153221538. [PubMed: 16853796]

79. Persson M, Harbridge JR, Hammarstrom P, Mitri R, Martensson LG, Carlsson U, Eaton GR, Eaton SS. Biophys J. 2001; 80:2886-2897. [PubMed: 11371461]

80. Jung ME, Gervay J. Tetrahedron Lett. 1988; 29:2429-2432. 
<smiles>CC(ON(C(c1ccccc1)c1ccccc1)C(C)(C)CCC(C)(C)N(OC(C)C(C)C)C(c1ccccc1)C(C)C)c1ccccc1</smiles>

1<smiles>CC(ON(C(c1ccccc1)C(C)C)C(C)(C)C)c1ccccc1</smiles>

2<smiles>[CH2-]ON(C(c1ccccc1)C(C)C)C(C)(C)C</smiles>

4<smiles>CON(C(c1ccccc1)C(C)C)C(C)(C)CCC(C)(C)N([O])C(c1ccccc1)C(C)C</smiles>

3<smiles>CC(ON1C(C)(C)CCCC1(C)C)c1ccccc1</smiles>

5

Figure 1.

Bisalkoxyamine 1, parent TIPNO-based initiator 2, bisnitroxide 3, 2,2,5-trimethyl-4phenyl-3-azahexane-3-nitroxide (TIPNO) 4, and 2,2,6,6-tetramethyl-1-(1phenylethoxy)piperidine $\mathbf{5}$. 


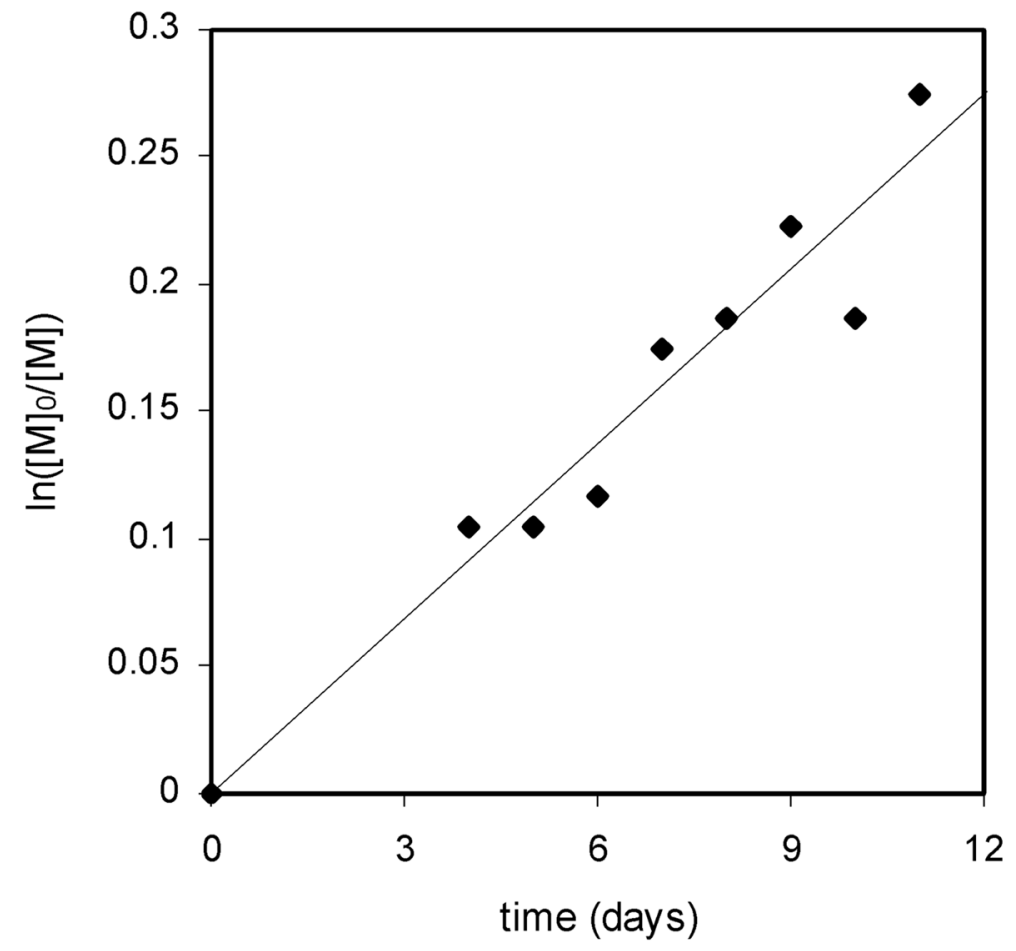

Figure 2.

Polymerization of tert-butyl acrylate with initiator $\mathbf{1}$ at $70^{\circ} \mathrm{C}$. The ratio of the initial monomer concentration $[\mathrm{M}]_{0}$ to the monomer concentration $[\mathrm{M}]$ at some later time was calculated from ${ }^{1} \mathrm{H}$ NMR integrations of the crude polymer samples. 


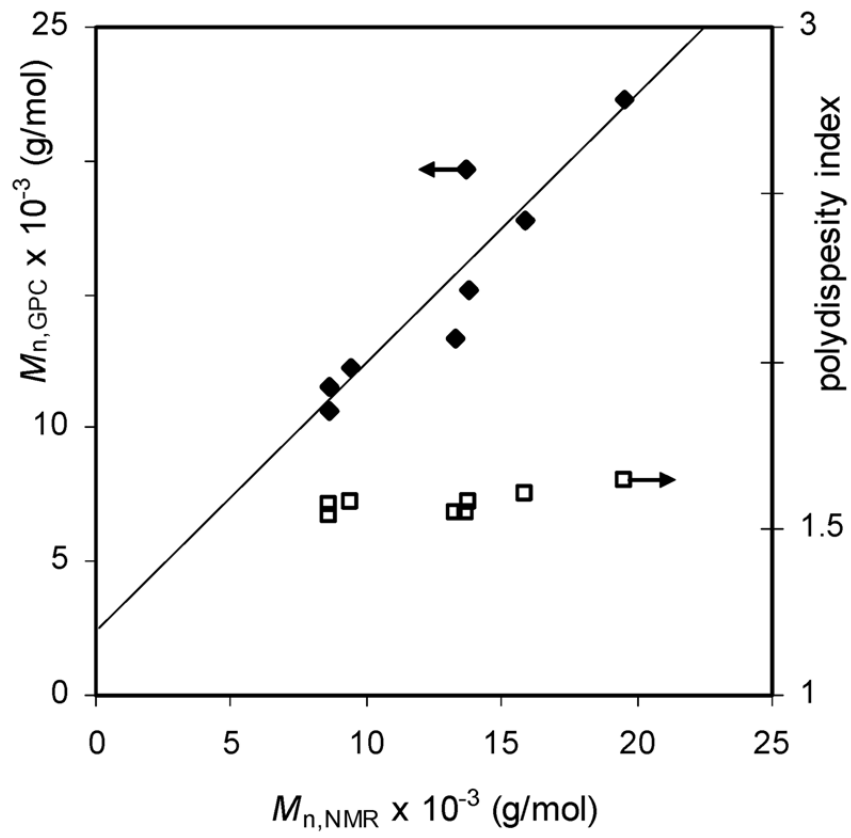

Figure 3.

Evolution of $M_{\mathrm{n}, \mathrm{GPC}}$ (number-average molecular weight determined by gel permeation chromatography and calibrated with polystyrene standards) and polydispersity index $\left(M_{\mathrm{W}} /\right.$ $M_{\mathrm{n}}$ ) as a function of $M_{\mathrm{n}, \mathrm{NMR}}$ (molecular weight calculated from ${ }^{1} \mathrm{H} \mathrm{NMR}$ ) for the polymerization of tert-butyl acrylate at $70{ }^{\circ} \mathrm{C}$ with bidirectional initiator 1 . 


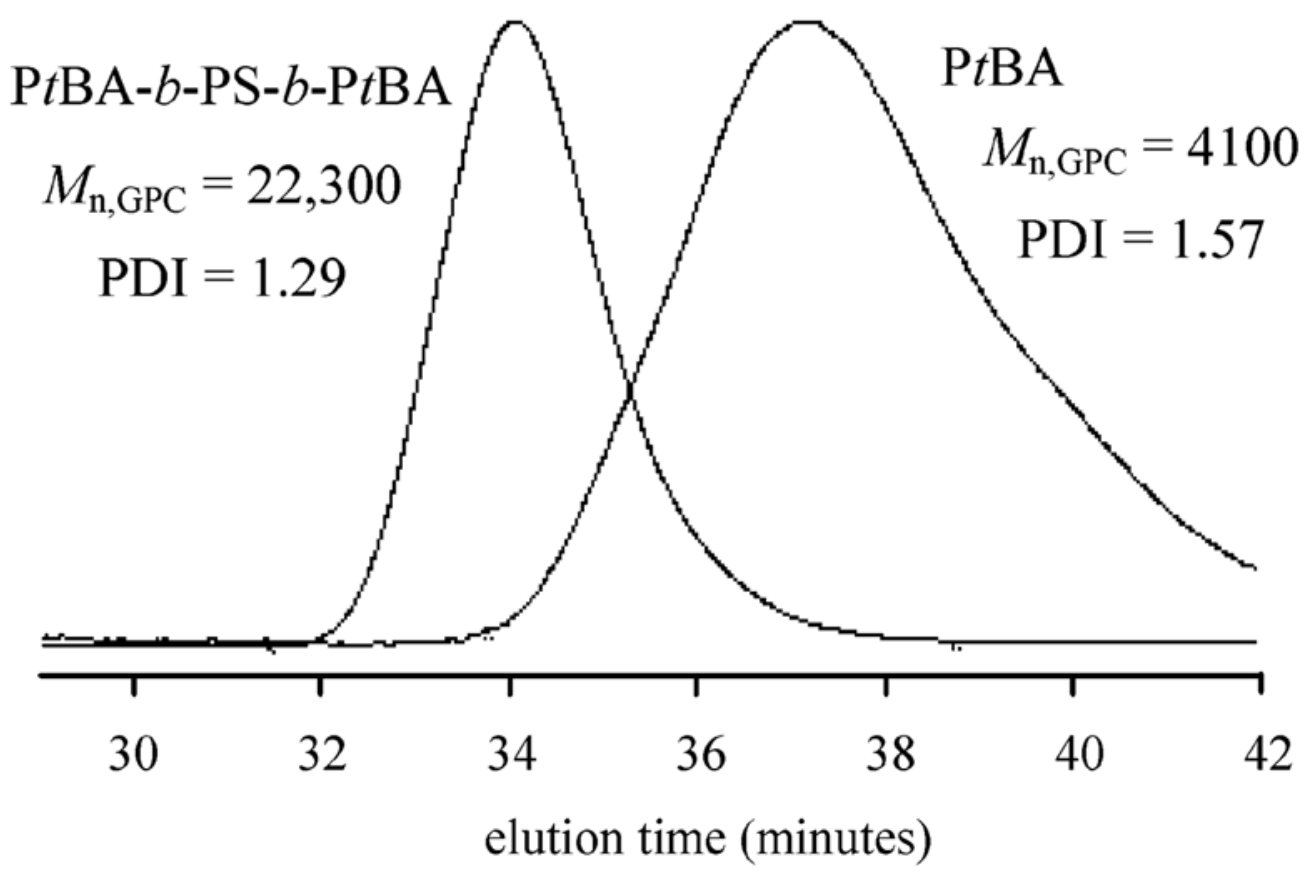

Figure 4.

Addition of a polystyrene B block to a poly(tert-butyl acrylate) A block macroinitiator to give an $\mathrm{ABA}$ P $t \mathrm{BA}-b$-PS- $b$-P $t \mathrm{BA}$ triblock copolymer. 


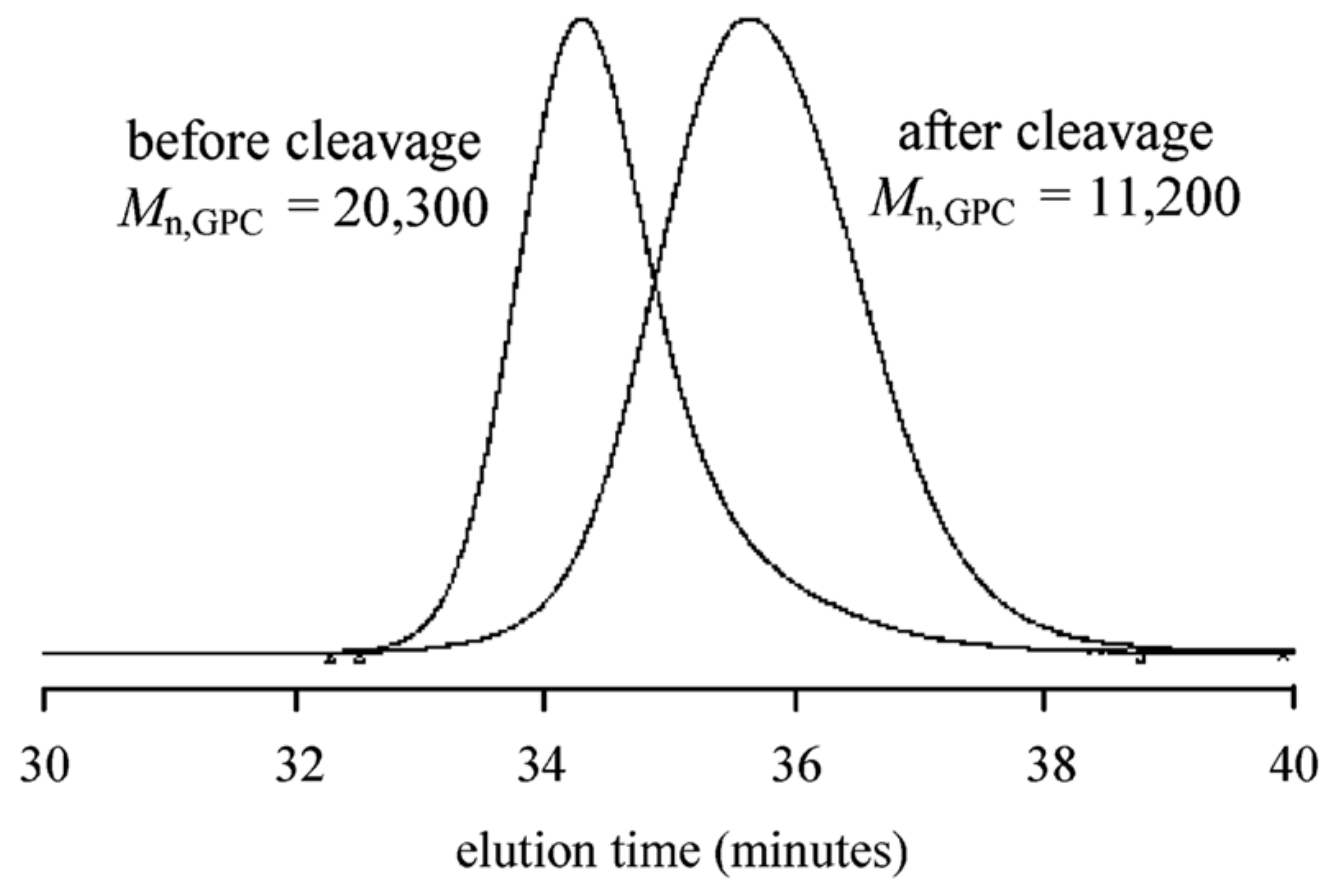

Figure 5.

Cleavage of internal bisnitroxide polystyrene sample prepared at $90{ }^{\circ} \mathrm{C}$ by heating to $130{ }^{\circ} \mathrm{C}$ in $p$-xylene for $16 \mathrm{~h}$. The resulting polymer is approximately half the original molecular weight as determined by gel permeation chromatography and calibrated with polystyrene standards (original sample: $M_{\mathrm{n}}=20300 \mathrm{~g} / \mathrm{mol}$; after cleavage: $M_{\mathrm{n}}=11200 \mathrm{~g} / \mathrm{mol}$ ). 


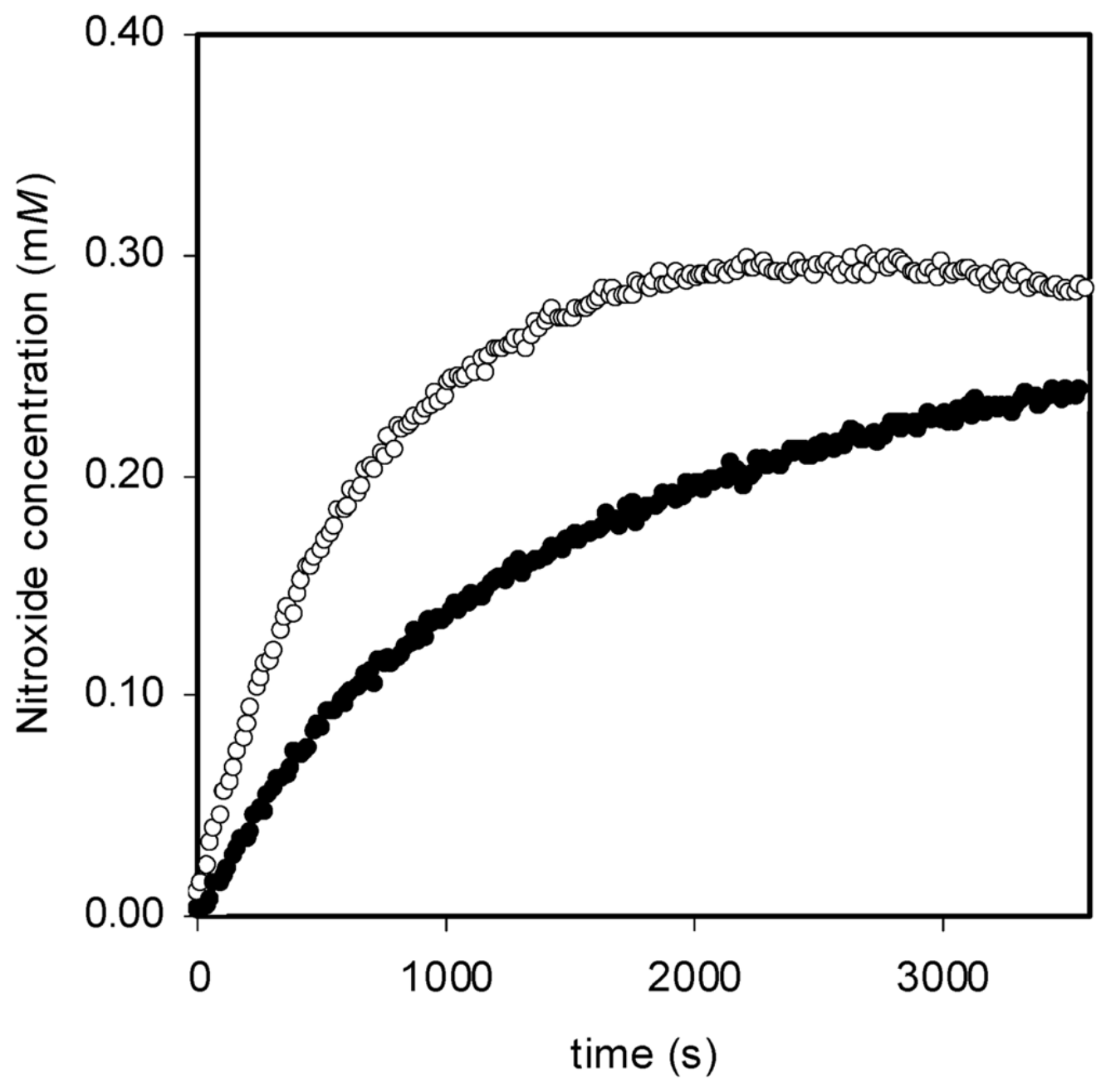

Figure 6.

Nitroxide concentration measured by EPR as a function of time for the homolysis of bisalkoxyamine initiator $\mathbf{1}(\circ)$ and parent alkoxyamine initiator $\mathbf{2}(\bullet)$ when heated at $363 \mathrm{~K}$ in tert-butylbenzene in the presence of oxygen. 


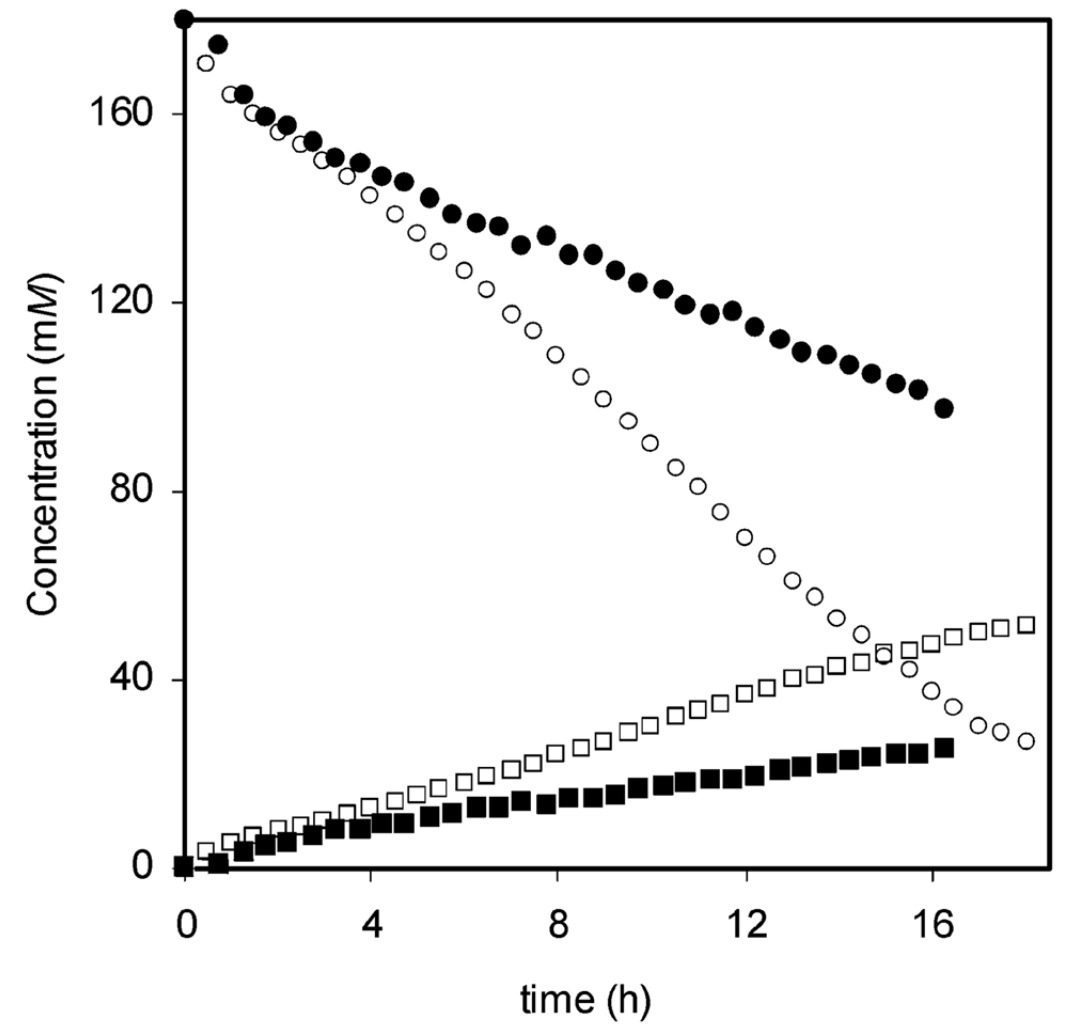

Figure 7.

Alkoxyamine $(\mathrm{A})$ and styrene $(\mathrm{S})$ concentrations as a function of time when bisalkoxyamine $\mathbf{1}(\mathrm{O}=[\mathrm{A}] ; \square=[\mathrm{S}])$ and parent alkoxyamine $\mathbf{2}(\bullet=[\mathrm{A}] ; \boldsymbol{\bullet}=[\mathrm{S}])$ were heated at $125{ }^{\circ} \mathrm{C}$ in $p$ xylene- $d_{10}$ in the absence of oxygen. Concentrations were calculated from $1 \mathrm{H}$ NMR integration values. 


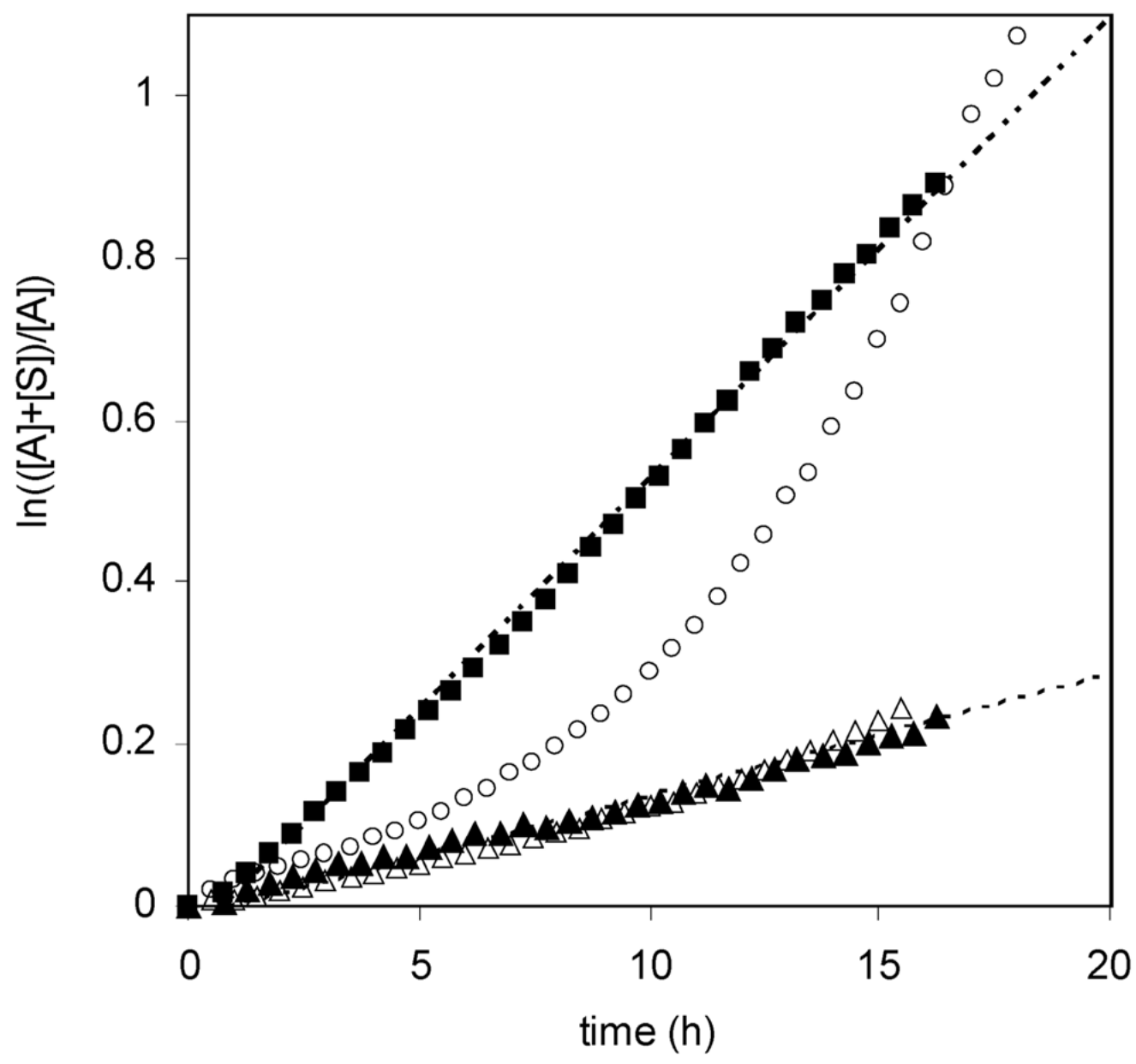

Figure 8.

Plot of $\ln (([\mathrm{A}]+[\mathrm{S}]) /[\mathrm{A}])$ as a function of time for bisalkoxyamine $\mathbf{1}\left(\mathrm{O},[\mathrm{A}]_{0}=180 \mathrm{mM}\right)$, parent alkoxyamine $2\left(\boldsymbol{\Lambda},[\mathrm{A}]_{0}=180 \mathrm{mM} ; \Delta,[\mathrm{A}]_{0}=90 \mathrm{mM}\right)$, and TEMPO-based alkoxyamine $5\left(\boldsymbol{m},[\mathrm{A}]_{0}=90 \mathrm{mM}\right)$ upon heating at $125^{\circ} \mathrm{C}$ in $p$-xylene- $d_{10}$ in the absence of oxygen. The concentrations of alkoxyamine functionality $[\mathrm{A}]$ and styrene $[\mathrm{S}]$ were measured by ${ }^{1} \mathrm{H}$ NMR integration values. 


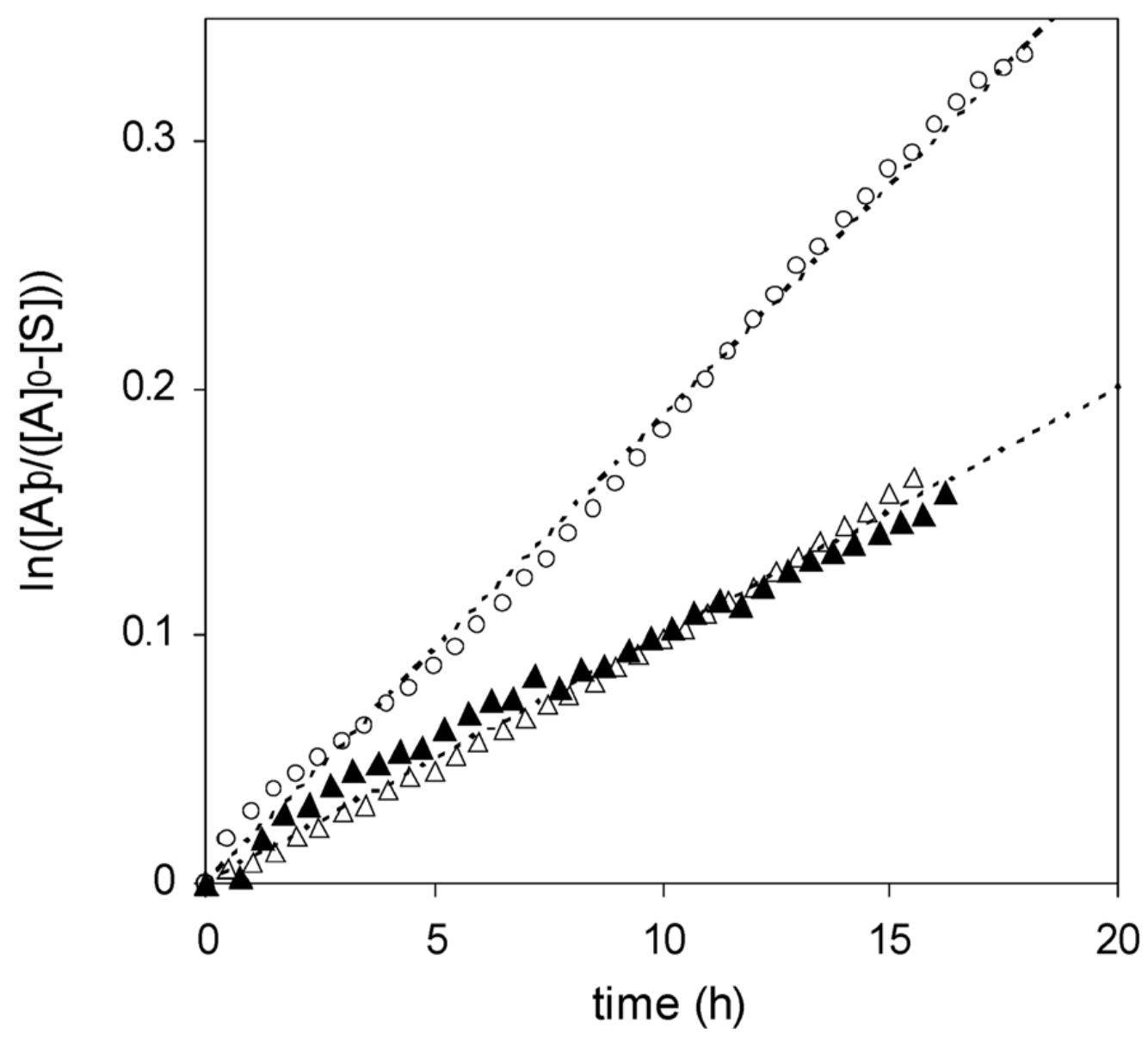

Figure 9.

Plot of $\ln \left([\mathrm{A}]_{0} /\left([\mathrm{A}]_{0}-[\mathrm{S}]\right)\right)$ as a function of time for bisalkoxyamine $\mathbf{1}\left(\mathrm{O},[\mathrm{A}]_{0}=180 \mathrm{mM}\right)$ and parent alkoxyamine $\mathbf{2}\left(\boldsymbol{\Delta},[\mathrm{A}]_{0}=180 \mathrm{mM} ; \Delta,[\mathrm{A}]_{0}=90 \mathrm{mM}\right)$ upon heating at $125{ }^{\circ} \mathrm{C}$ in $p$-xylene $d_{10}$ in the absence of oxygen. The concentration of styrene $[\mathrm{S}]$ was measured by ${ }^{1} \mathrm{H}$ NMR integration values, and $[\mathrm{A}]_{0}$ is the initial concentration of alkoxyamine functionality. 


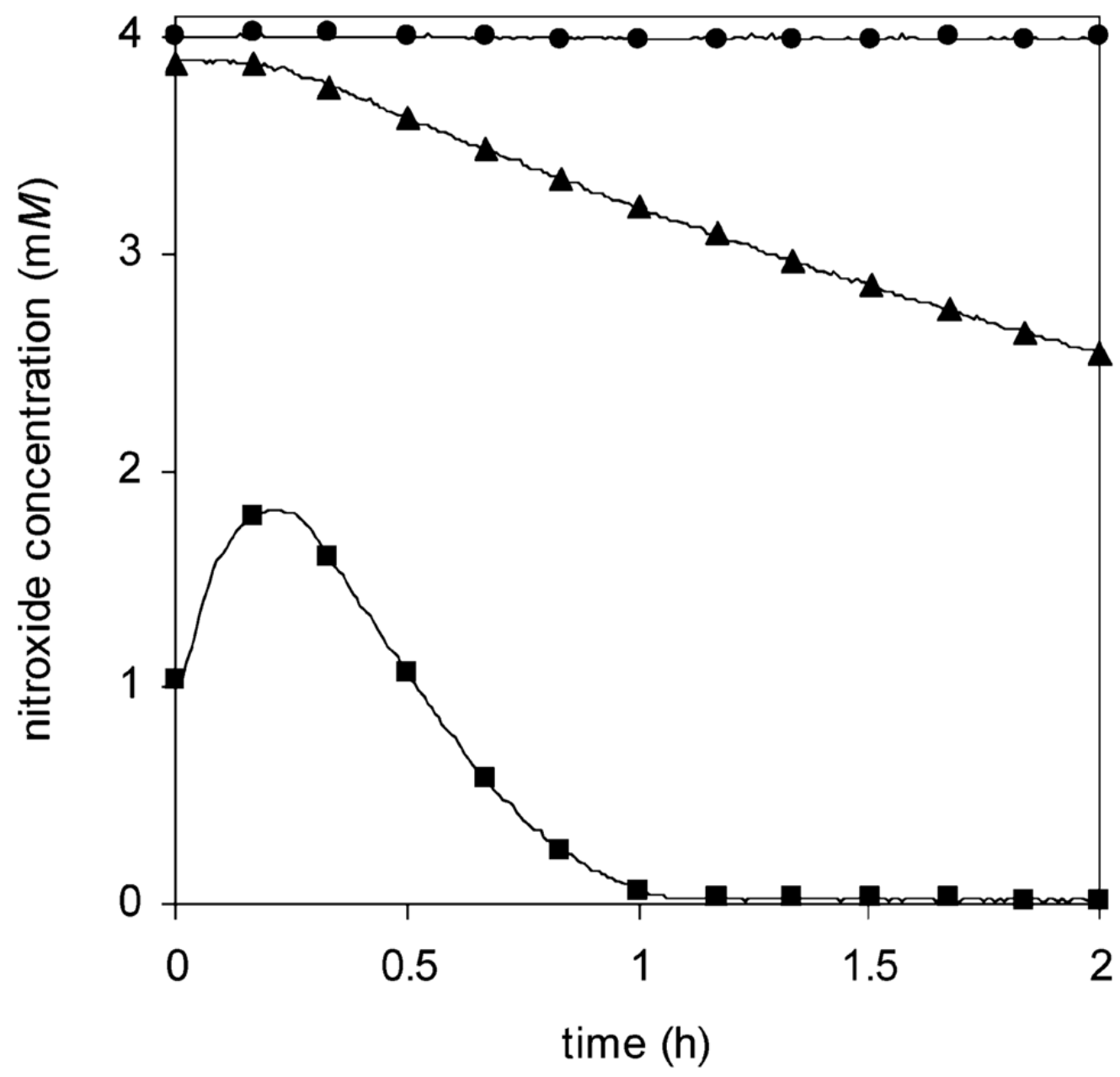

Figure 10.

Variation of nitroxide concentration with time upon heating of bisnitroxide $\mathbf{3}(\mathbf{\square})$, mononitroxide $4(\boldsymbol{\Delta})$, and TEMPO $(\bullet)$ at $120^{\circ} \mathrm{C}$ in tert-butylbenzene. Scans were taken every 30 to $60 \mathrm{~s}$; only a small selection of data points are shown for clarity. Nitroxide samples $\mathbf{3}$ and $\mathbf{4}$ were synthesized, purified by flash chromatography, and stored in tertbutylbenzene at $0{ }^{\circ} \mathrm{C}$ for 1 day prior to use. 


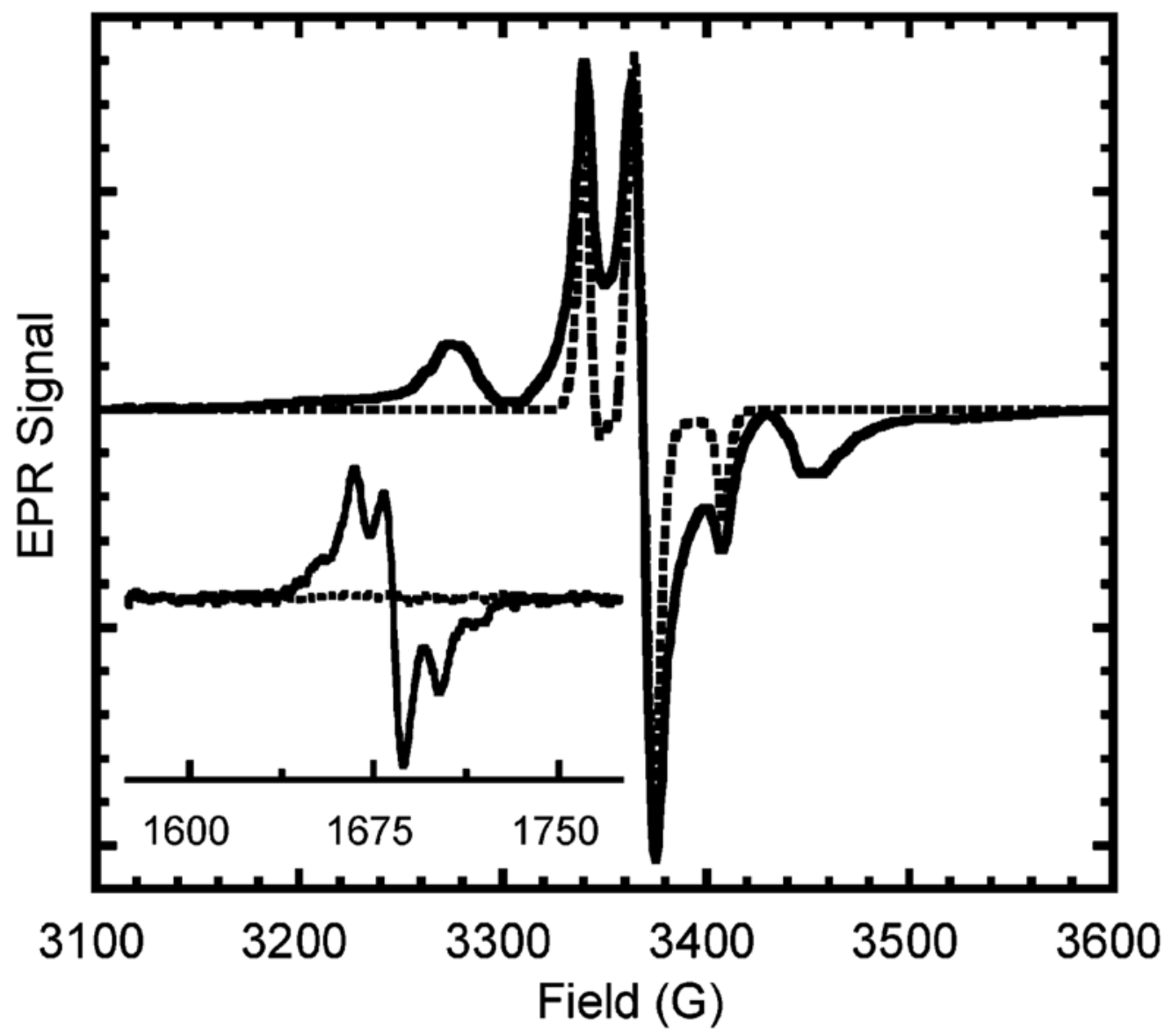

Figure 11.

EPR spectra of bisnitroxide 3 (solid line) and TIPNO mononitroxide 4 (dashed line). Spectra peak heights are normalized. Inset shows the half-field transition for $\mathbf{3}$; the intensity is not to scale. 


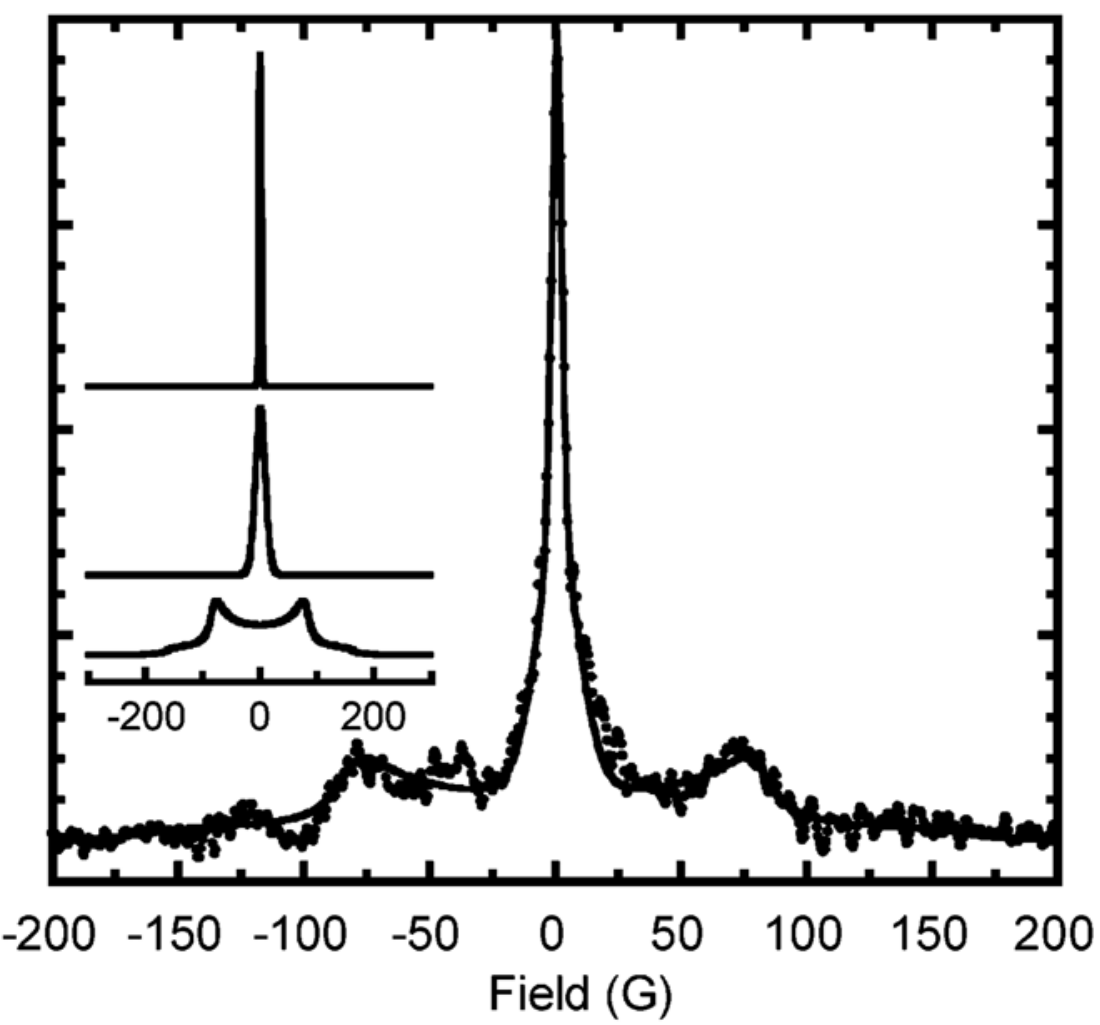

Figure 12.

Dipolar broadening function. The dipolar broadening function (dots) was determined by Fourier transform deconvolution of the bisnitroxide EPR spectrum with the mononitroxide TIPNO spectrum. The simulated broadening function (solid line) is the sum of the three functions shown in the inset. They are, from the top, a narrow Gaussian $(2.25 \mathrm{G} \mathrm{fwhm}$ and $9 \%$ of total area), a broader Gaussian (20 G fwhm and $30 \%$ of total area), and a "Pake" function $(150 \mathrm{G}$ wide and $61 \%$ of total area). 


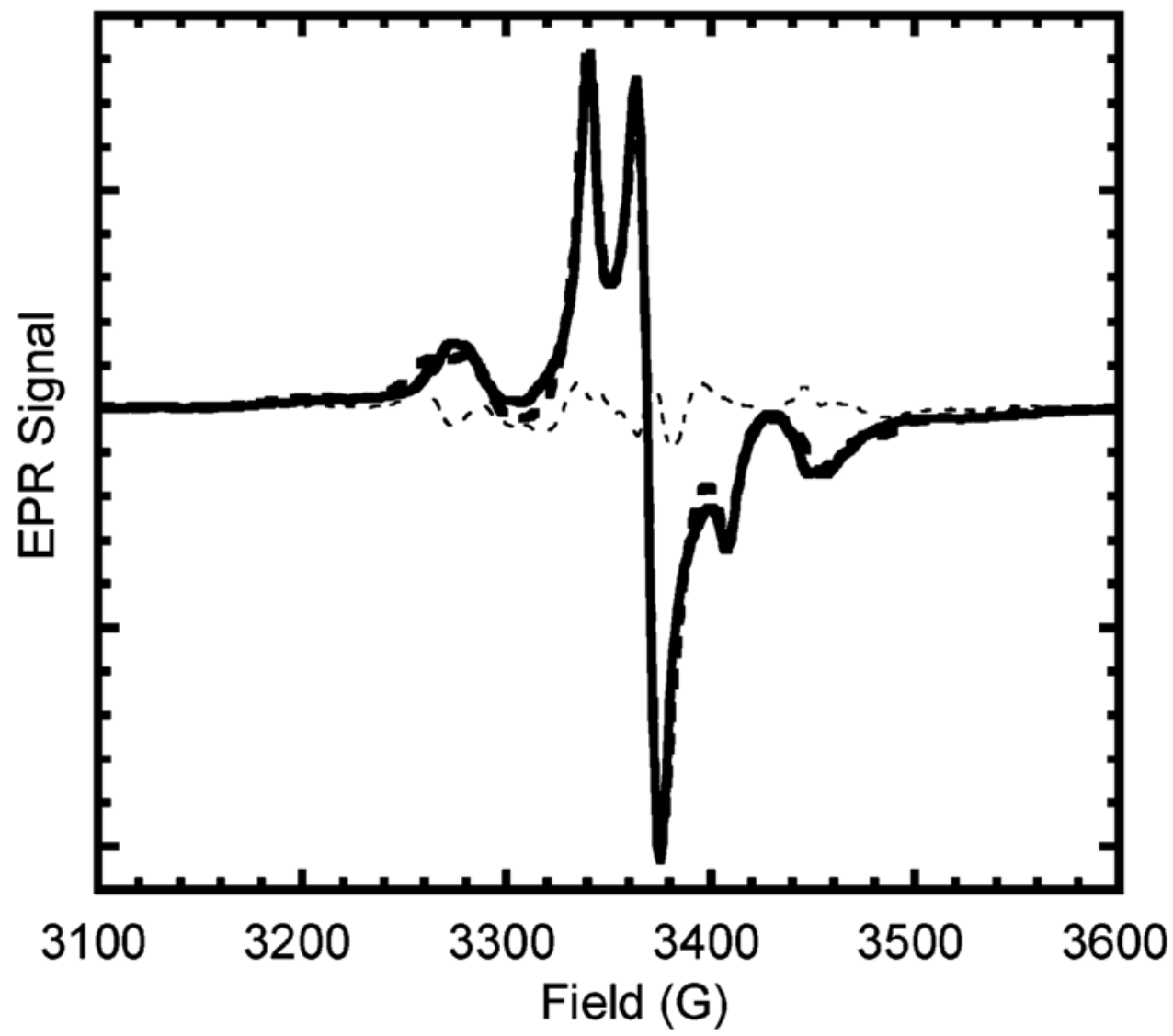

Figure 13.

Simulation of experimental spectrum. The experimental EPR spectrum of the bisnitroxide 3 (solid line) was simulated by the convolution of the TIPNO 4 spectrum with the simulated broadening function (dashed line) from Figure 10. Also shown is the residual signal (dotted line). 


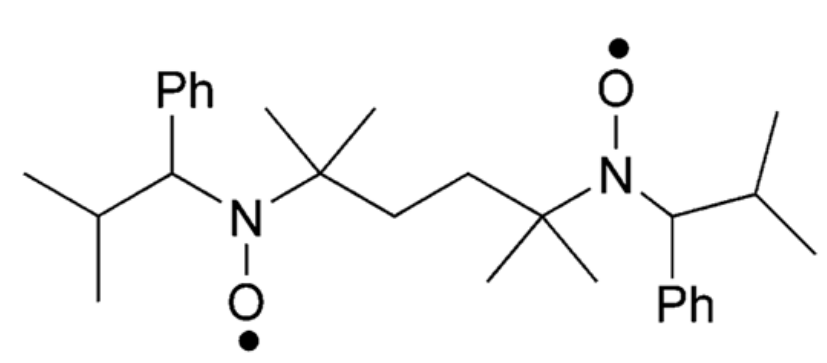

6

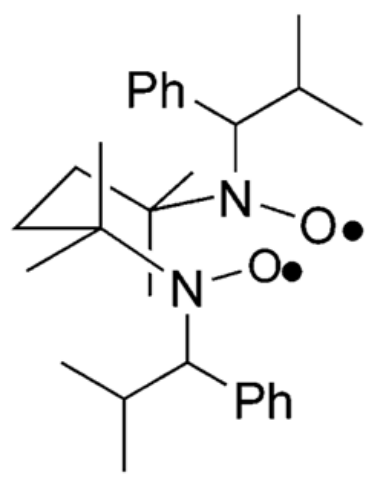

7

Figure 14.

Nonassociated nitroxides with a distance of $9.8 \AA(6)$ and interacting nitroxides with a distance of $5.8 \AA$ (7). 


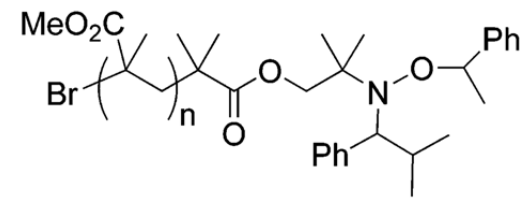

8

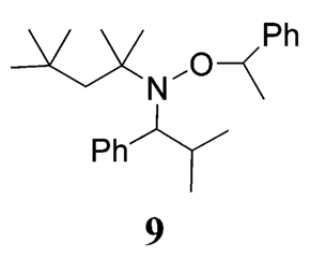

9

Figure 15.

Alkoxyamine initiators structurally similar to $\mathbf{1}$ : polymeric initiator $\mathbf{8}$ containing a macromolecular nitroxide ${ }^{48}$ and Studer's sterically congested neopentyl initiator 9. 31 

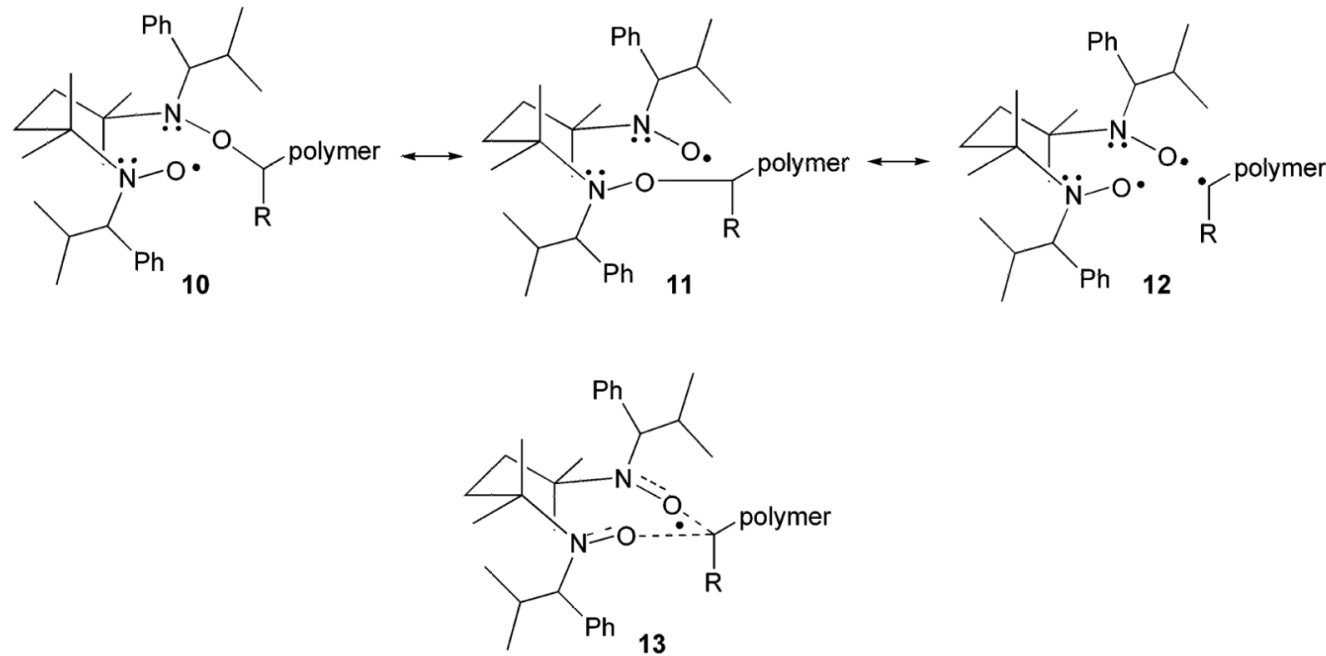

Figure 16.

Proposed resonance structures of the key nitroxide intermediate during polymerization. 

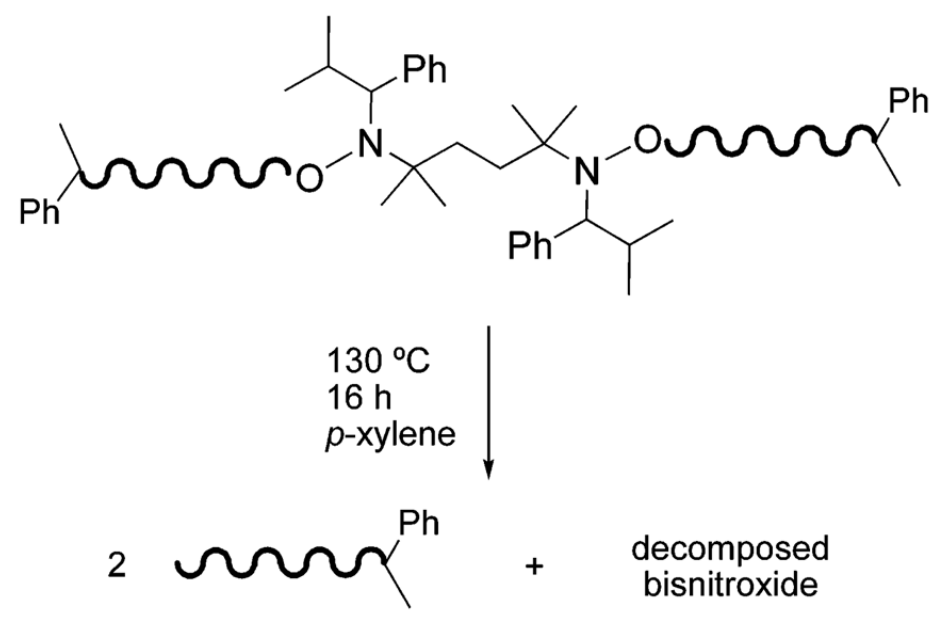

Scheme 1.

Thermolytic Cleavage of a Polymer Containing an Internal Bisnitroxide 


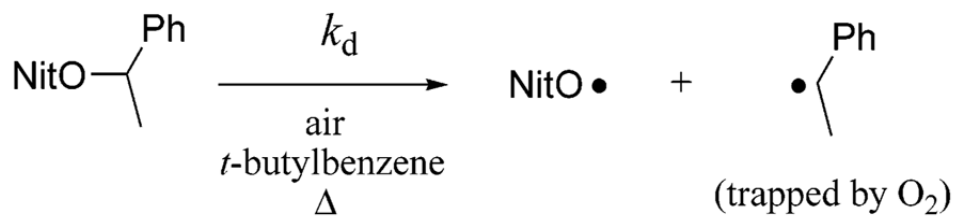

Scheme 2.

Alkoxyamine Dissociation Reaction Used To Determine $k_{\mathrm{d}}$, where NitO Represents a Nitroxide 


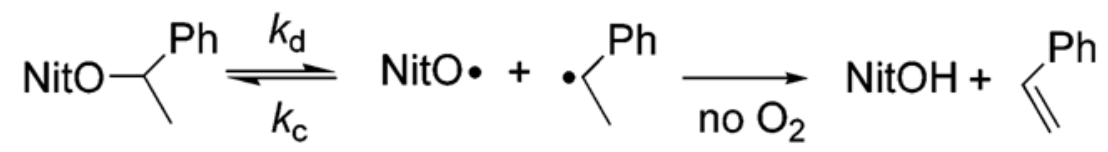

A

Scheme 3.

Decomposition of $N$-Alkoxyamine (A) by Extended Thermolysis To Give Hydroxylamine and Styrene (S), where NitO Represents a Nitroxide 
<smiles>[R]C(CO)O[Na]</smiles><smiles>CC1CCCCC1</smiles>

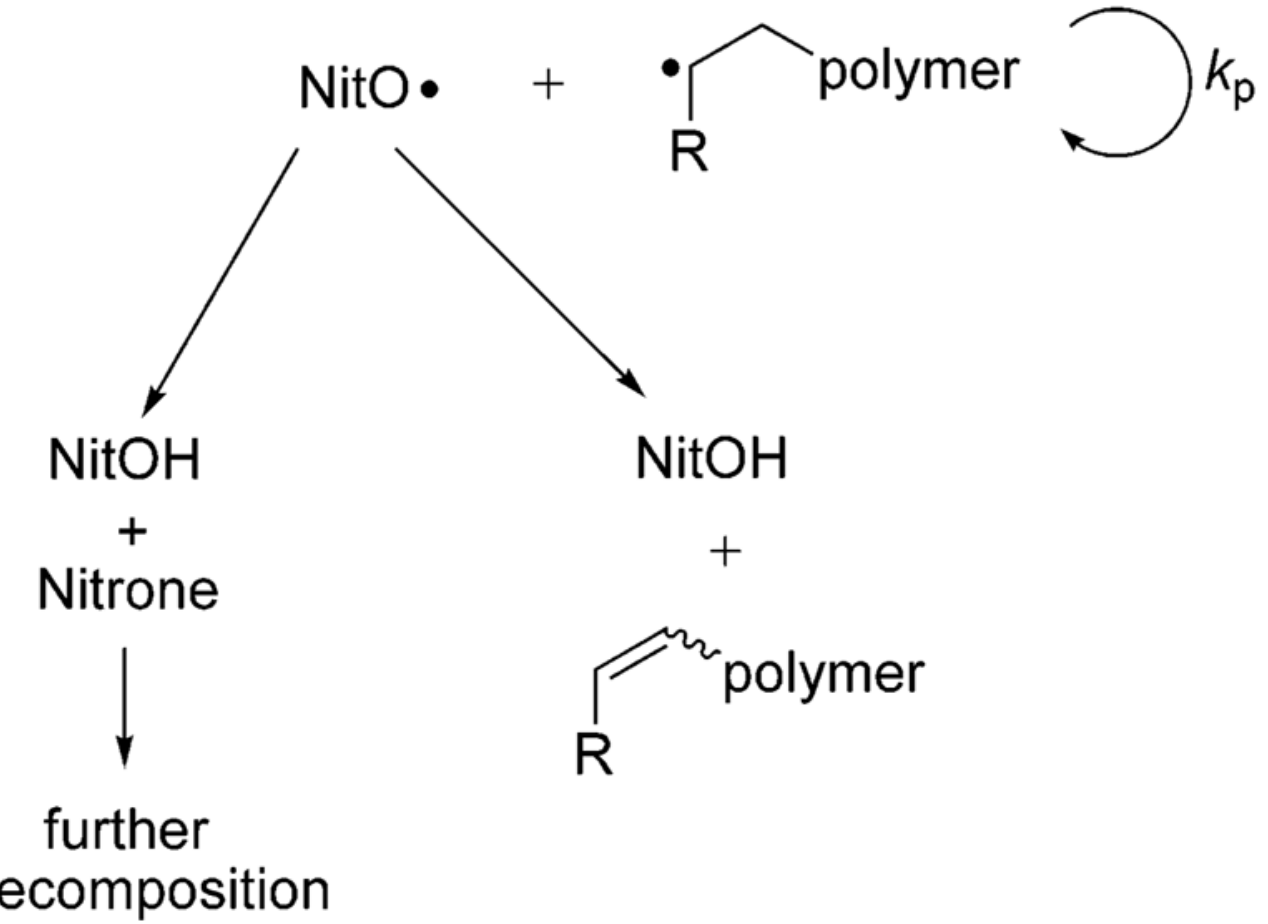

Scheme 4.

Key Reactions during Nitroxide-Mediated Radical Polymerization, where NitO Represents a Nitroxide 


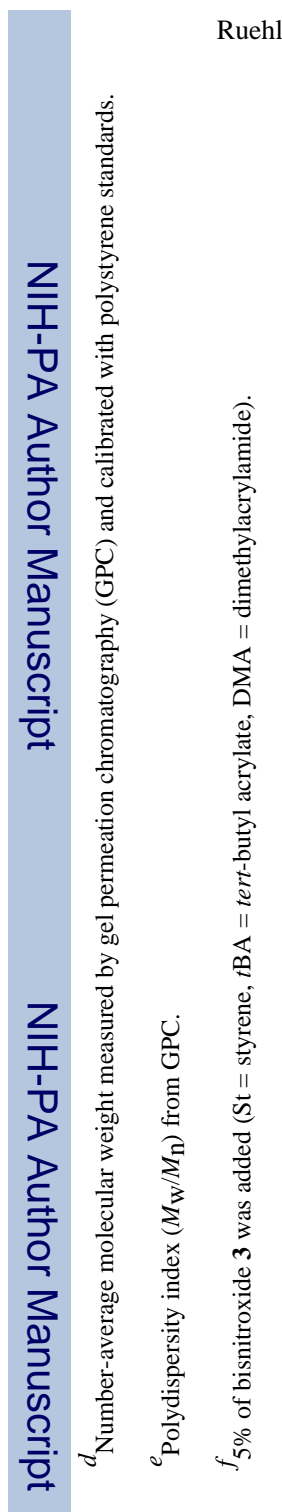

Page 36

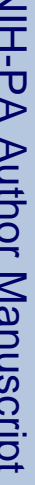

Macromolecules. Author manuscript; available in PMC 2011 May 10. 
Table 2

Central Cleavage $^{a}$ of Polymers Prepared with Bisalkoxyamine Initiator 1

\begin{tabular}{|c|c|c|c|c|}
\hline \multirow[b]{2}{*}{ monomer } & \multicolumn{2}{|l|}{ original } & \multicolumn{2}{|l|}{ after cleavage } \\
\hline & $M_{\mathrm{n}, \mathrm{GPC}}{ }^{b} \times 10^{-4}(\mathrm{~g} / \mathrm{mol})$ & $\mathrm{PDI}^{c}$ & $M_{\mathrm{n}, \mathrm{GPC}}{ }^{b} \times 10^{-4}(\mathrm{~g} / \mathrm{mol})$ & $\mathrm{PDI}^{d}$ \\
\hline $\mathrm{St}^{e}$ & 2.03 & 1.16 & 1.12 & 1.17 \\
\hline$t \mathrm{BA}^{e}$ & 2.09 & 1.38 & 1.49 & 1.42 \\
\hline $\mathrm{St}^{f}$ & 0.80 & 1.24 & 0.33 & 1.62 \\
\hline$t \mathrm{BA}^{f}$ & 0.78 & 1.43 & 0.52 & 1.63 \\
\hline \multicolumn{5}{|c|}{${ }^{a}$ Samples were heated as $1.2 \mathrm{mM}$ solutions in $p$-xylene for $16 \mathrm{~h}$. } \\
\hline \multicolumn{5}{|c|}{$b$ Number-average molar mass measured by gel permeation chromatography (GPC) and calibrated with polystyrene standards. } \\
\hline \multicolumn{5}{|c|}{ Polydispersity index $\left(M_{\mathrm{W}} / M_{\mathrm{n}}\right)$ from GPC before cleavage. } \\
\hline \multicolumn{5}{|c|}{${ }^{d}$ Polydispersity index $\left(M_{\mathrm{W}} / M_{\mathrm{n}}\right)$ from GPC after cleavage. } \\
\hline
\end{tabular}




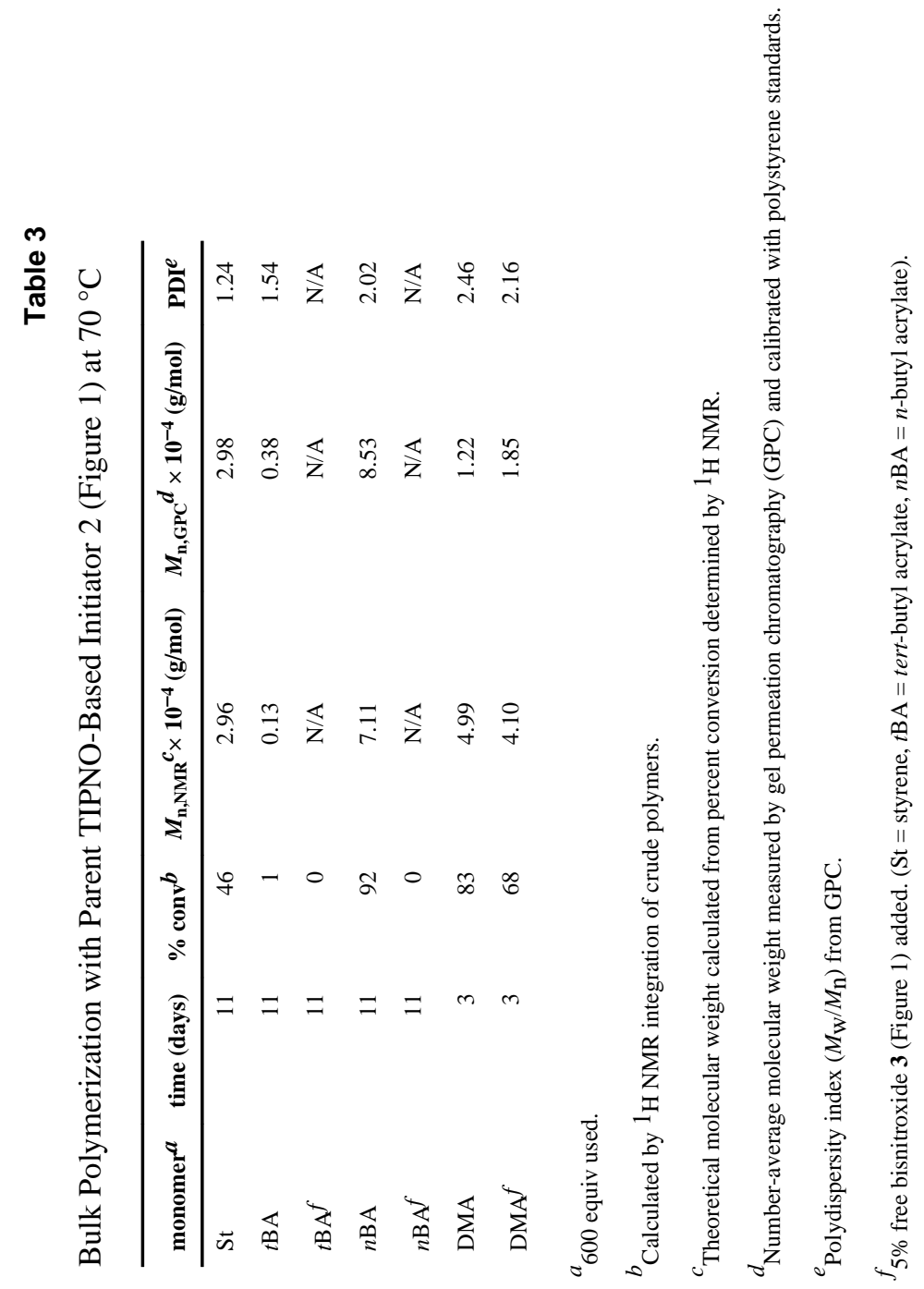

Macromolecules. Author manuscript; available in PMC 2011 May 10. 
Table 4

Kinetic Data for the Homolytic Dissociation of Bisalkoxyamine Initiator 1 Compared to Parent Initiator 2 in tert-Butylbenzene

\begin{tabular}{llll}
\hline & bisalkoxyamine 1 & monoalkoxyamine 2 & lit. value for 2 \\
\hline$k_{358}\left(\mathrm{~s}^{-1}\right)$ & $1.6 \times 10^{-4}$ & $8.3 \times 10^{-5}$ & $6.9 \times 10^{-5 a}$ \\
$k_{363}\left(\mathrm{~s}^{-1}\right)$ & $3.3 \times 10^{-4}$ & $1.6 \times 10^{-4}$ & $1.3 \times 10^{-4 a}$ \\
$k_{368}\left(\mathrm{~s}^{-1}\right)$ & $5.2 \times 10^{-4}$ & $2.3 \times 10^{-4}$ & $2.2 \times 10^{-4 a}$ \\
$k_{373}\left(\mathrm{~s}^{-1}\right)$ & $9.2 \times 10^{-4}$ & $4.8 \times 10^{-4}$ & $4.0 \times 10^{-4 a}$ \\
$k_{378}\left(\mathrm{~s}^{-1}\right)$ & $1.2 \times 10^{-3}$ & $6.1 \times 10^{-4}$ & $6.9 \times 10^{-4 a}$ \\
$E_{\mathrm{a}}(\mathrm{kJ} / \mathrm{mol})$ & 113 & 115 & 130 \\
$A\left(\mathrm{~s}^{-1}\right)$ & $5.3 \times 10^{12}$ & $4.7 \times 10^{12}$ & $5.6 \times 10^{14}$ \\
${ }^{a}$ Calculated using reported values & &
\end{tabular}




\section{Table 5}

Kinetic Data for the Decomposition of Alkoxyamines 1,2 , and 5 at $125^{\circ} \mathrm{C}$ in $p$-Xylene- $d_{10}$ in the Absence of Oxygen

\begin{tabular}{cccll}
\hline alkoxyamine & $\boldsymbol{k}_{\mathrm{dec}} / \mathbf{s}^{-\mathbf{1}}$ (from eq 2) & $\boldsymbol{k}_{\mathrm{dec}} / \mathbf{s}^{-\mathbf{1}}($ from eq 4) & $\boldsymbol{k}_{\mathrm{d}} / \mathbf{s}^{-\mathbf{1}}$ & $\boldsymbol{p}_{\mathrm{dec}}$ \\
\hline $\mathbf{1}$ & & $5.2 \times 10^{-6}$ & $8.1 \times 10^{-3}$ & $6.4 \times 10^{-4}$ \\
$\mathbf{2}$ & $3.7 \times 10^{-6}$ & $2.8 \times 10^{-6}$ & $4.2 \times 10^{-3}$ & $(8.8-6.6) \times 10^{-4}$ \\
$\mathbf{5}$ & $1.6 \times 10^{-5}$ & & $8.0 \times 10^{-4 a}$ & $2.0 \times 10^{-2}$ \\
& & & \\
${ }^{a}$ Calculated using reported values & & & \\
&
\end{tabular}

